September 2008 | Volume 96 | Number 9

Proceedings

\title{
SELF-ASSEMBLY AT THE MACROSCOPIC SCALE
}

Energy Harvesting for Wireless Devices Modeling of Nanoscale Devices

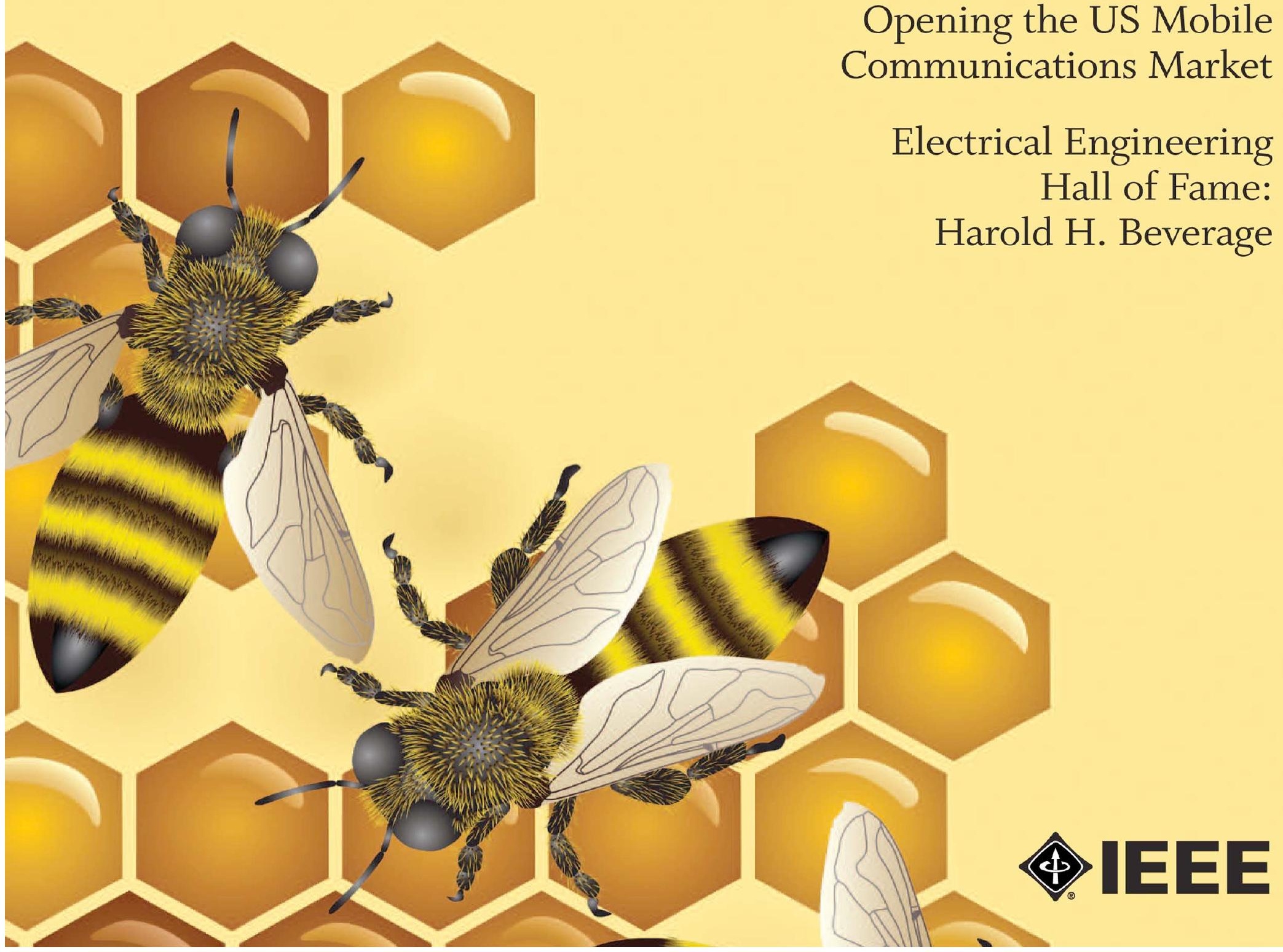

Point of View:

Opening the US Mobile Communications Market

Electrical Engineering Hall of Fame: Harold H. Beverage 


\title{
Self-Assembly at the Macroscopic Scale
}

\author{
An impressive variety of systems have been designed with capabilities such as \\ forming, growing, reconfiguring, repairing and replicating themselves, based on \\ information coded in their components.
}

By Roderich Groß, Member IEEe, and Marco Dorigo, Fellow IEEE

\begin{abstract}
In this paper, we review half a century of research on the design of systems displaying (physical) self-assembly of macroscopic components. We report on the experience gained in the design of 21 such systems, exhibiting components ranging from passive mechanical parts to mobile robots. We present a taxonomy of the systems and discuss design principles and functions. Finally, we summarize the main achievements and indicate potential directions for future research.
\end{abstract}

KEYWORDS | Brownian motion; formation; growth; macroscopic; modular robotics; self-assembly; self-propelled; selfreconfiguration; self-repair; self-replication; taxonomy

\section{INTRODUCTION}

Self-assembly processes are responsible for the generation of order in nature. They involve components at different scales, such as molecules, cells, organisms, and weather systems. Scientists across many disciplines believe that the study of physical models of self-assembly can help in understanding nature and in advancing technology.

Following Whitesides and Grzybowski [113], selfassembly can be defined as a process by which preexisting components ("separate or distinct parts of a disordered structure") autonomously organize into patterns or structures without human intervention. In this paper, we focus on

\footnotetext{
Manuscript received March 23, 2007; revised April 27, 2008. The work of R. Groß was supported by the Marie Curie Transfer of Knowledge project BRIDGET, European Commission, under Contract MKTD-CD-2005-029961 and by a Marie Curie Intra-European Fellowship under Contract MEIF-CT-2006-040312. The work of M. Dorigo was supported by IST FET project SWARMANOID, European Commission, under Contract IST-022888 and by F.R.S.-FNRS, Belgium.

R. Groß was with the School of Biological Sciences, University of Bristol, Bristol, U.K., and Unilever R\&D Port Sunlight, Bebington, U.K. He is now with the Laboratoire de Systèmes Robotiques, Ecole Polytechnique Fédérale de Lausanne, CH-1015 Lausanne, Switzerland (e-mail: roderich.gross@ieee.org).

M. Dorigo is with IRIDIA, CoDE, Université Libre de Bruxelles, B-1050 Brussels, Belgium (e-mail: mdorigo@ulb.ac.be).
}

Digital Object Identifier: 10.1109/JPROC.2008.927352 processes i) in which components (physically) bind together and ii) that can be controlled by proper design of the components.

Self-assembly processes are governed by information coded in the components. In biological systems, for instance, the component design undergoes evolution as the structure resulting from the components' interactions is selected for specific functions [2], [16], [53], [99]. In general, the design allows components to selectively bind to, and/or selectively disband from, each other (e.g., based on shape recognition). Note that processes that occur within aggregates of preassembled components may fall into the same general category as self-assembly. Such metamorphic processes (e.g., [1], [19], [78], [103], [123]) are not treated in this paper.

Selective binding is widely observed, for instance, in the assembly of the DNA double helix. It regulates the replication of genetic information and makes the process intrinsically self-correcting [94]. Ants of the species Ecophylla longinoda [68], [69] are another example that, if offered two alternative sites to bridge an empty space, typically end up in a single, large, self-assembled aggregate in either one of the two sites. Here, selective binding occurs, for example, in the form of preferences to assemble to (or disassemble from) aggregates of different sizes.

Previous surveys of self-assembling systems provide a general overview of systems ranging from the molecular to the planetary scale [113], treat natural systems [2], [53], [99], or focus on systems at the molecular or mesoscopic scale [8], [94]. In this paper, we review artificial systems at the macroscopic scale. These systems consist of centimeter-sized components, which currently are the biggest available in man-made self-assembling systems.

Systems at the macroscopic scale present some interesting characteristics:

i) The component design can be precisely controlled.

ii) The logic of existing components can be reprogrammed by simple means. 
iii) Modules can exhibit complex dynamic behaviors involving thousands of internal states.

iv) Modules can be equipped with a range of sensors providing feedback from the environment.

v) Modules can interact via communication.

vi) Self-assembly processes can be easily monitored and analyzed (by the components themselves or by external observers).

In this paper, we present a comprehensive collection of systems for which self-assembly has been demonstrated. The diversity of the examples and the present lack of a theoretical framework are parts of the picture that we wish to convey. In general, two distinct classes of systems exist (Sections II and III, respectively): i) systems in which the components (that self-assemble) are externally propelled and ii) systems in which the components (that selfassemble) are self-propelled. We provide a taxonomy that allows one to identify relations among the different systems and to extract some principles in the design of self-assembling systems (Section IV). We summarize the main achievements and identify potential direction for future research (Section V) and then conclude this paper (Section VI).

\section{SELF-ASSEMBLY OF EXTERNALLY PROPELLED COMPONENTS}

In this section, we focus on systems in which the components are externally propelled. Components up to the microscopic scale, if suspended in a fluid, exhibit "Brownian motion" as the system is agitated thermally [14], [25]. At the macroscopic scale, however, the underlying thermal effects are irrelevant. Thus, propulsion requires external agitation apparatuses. To increase the rate at which components encounter each other, the system environment is bounded and components are relatively numerous.

In this section, we present ten systems whose components are externally propelled. The components that self-assemble are the system's building blocks as well as the intermediate products of the self-assembly process. In the following, we use the term modules to refer to a system's basic building blocks.

\section{A. Penrose's Template-Replicating Modules}

Half a century ago, L. S. Penrose and R. Penrose built the first known physical model of a self-replicating machine [93]. The system, which is of purely mechanical nature, is illustrated in Fig. 1. It comprises two types of modules that move randomly on a linear track. Each module has a state, which is expressed by its orientation relative to the track. A module's orientation can be horizontal or inclined to either the left or the right side. The system is capable of replicating two distinct template structures [one such template is shown in Fig. 1(b)]. The replicant equals the template with regard to the number and type of modules, as well as the modules' state. In follow-up works [90]-[92], L. S. Penrose went on to develop more complex replicating systems, including a system composed of homogeneous modules. The design of this system was also extended to two dimensions.

\section{B. Hosokawa et al.'s Self-Assembling Hexagons}

Hosokawa et al. [57] analyzed the dynamics of selfassembly formation in a system composed of simple, homogeneous modules. The modules reside in a flat box, which rotates in a vertical plane [see Fig. 2(a)]. Differently from Penrose's system, the modules do not have any state. However, a simple logic is implemented by the anisotropic binding preferences. The module's layout is an equilateral triangle with permanent magnets of opposite polarization in two of its sides. At most six modules can bind together, forming this way a hexagon.

The authors describe potential transitions among initial, intermediate, and final products by a system of "chemical" reactions. The state of the system is expressed in the quantities of every product. Probabilities for state transitions are estimated based on geometrical consideration. The yield of hexagons in a system of 20 modules, that is, the amount of hexagons the system produces, was estimated by calculation, and the estimate was compared to the average yield obtained in 100 experimental trials. A similar comparison was made for the state dynamics in a system of 100 modules. For the system of 20 modules, the authors used a method "known as the master equation [52]," which considers the dynamics of probability distributions. They reported that this method was "not suitable if $N$ [the number of components] is greater than this order." For the system of 100 modules, the authors

(a)

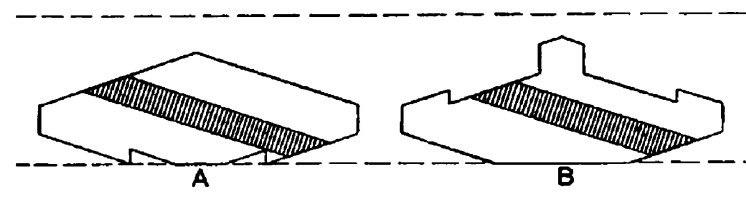

(b)

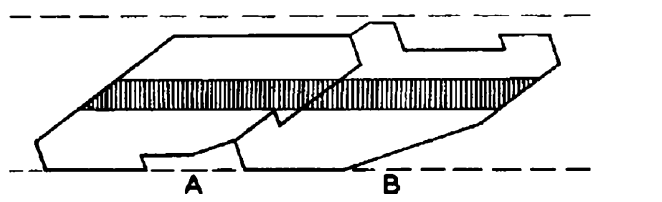

Fig. 1. Illustration of Penrose's simple model of self-replication. Adapted by permission from Macmillan Publishers Ltd: Nature [93], copyright (1957).The system comprises two types of modules $A$ and B. Modules of both types are put in random sequence on a linear track that is blocked at both ends. The system is subject to side-to-side agitation. (a) In their default position modules do not link under the influence of shaking alone. (b) If a seed object composed of an $A$ module and a $B$ module is added, identical objects will self-assemble at any point on the track where an $A$ module happens to be immediately on the left of a B module. If the experiment is repeated, with the seed object being inclined in the opposite direction, a complementary aggregate is built. The system is thus capable of 1-bit replication. 


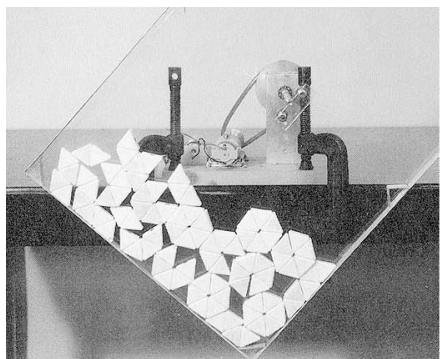

(a)

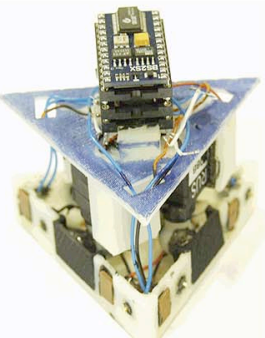

(d)

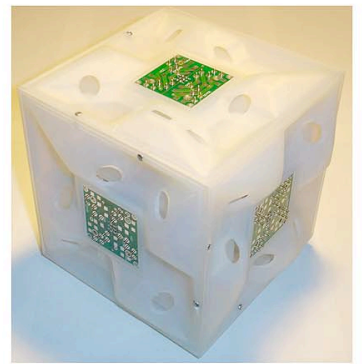

(g)

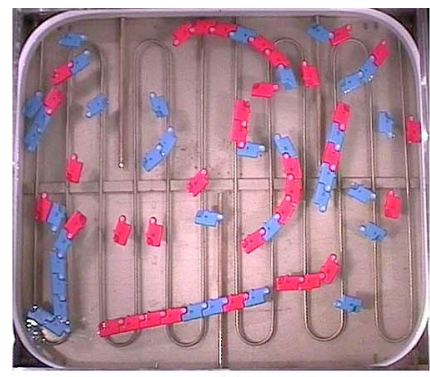

(b)

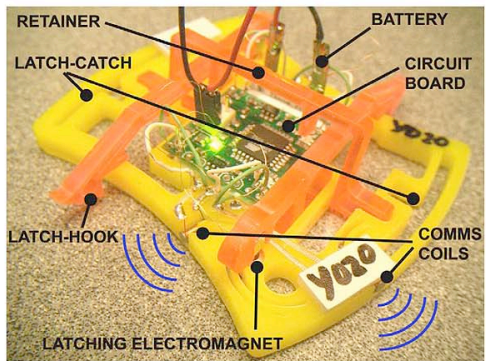

(e)

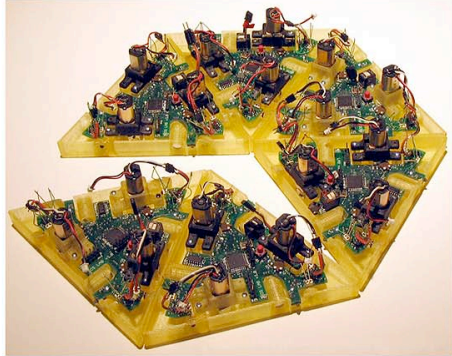

(h)

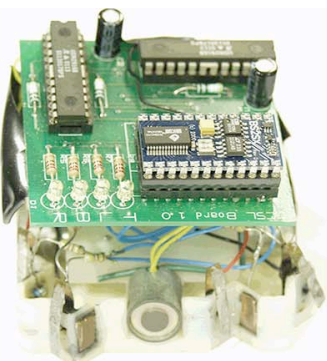

(c)

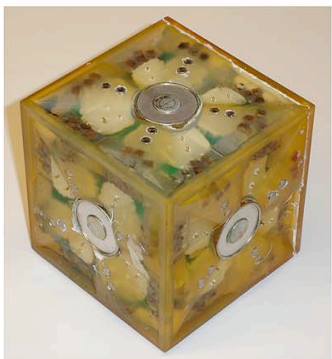

(f)

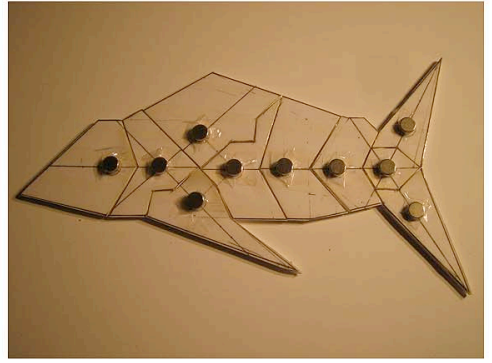

(i)

Fig. 2. Systems with externally propelled components: (a) Hosokawa et al.'s self-assembling hexagons (reprinted by permission from MIT Press: Artificial Life [57]). (b) Breivik's template-replicating polymers [12] (photo courtesy of J. Breivik, University of Oslo). (c), (d) White et al.'s self-assembling programmable modules (photo courtesy of P. J. White et al., Cornell University). (e) Griffith et al.'s electromechanical assemblers [reprinted by permission from Macmillan Publishers Ltd: Nature [43], copyright (2005)]. (f) White et al.'s first system for self-assembly in 3-D (photo courtesy of P. White and H. Lipson, Cornell University). (g) White et al.'s second system for self-assembly in 3-D (photo courtesy of P. White et al., Cornell University). (h) Programmable parts testbed (photo courtesy of E. Klavins, University of Washington). (i) Bhalla and Bentley's self-assembling special purpose modules (photo courtesy of N. Bhalla and P. J. Bentley, University College London).

used a different method, which considers the dynamics of mean values.

The authors propose a second design, in which a module can be in either active or passive state. Stable bindings between two modules can occur only if at least one of them is in the active state. Modules in the passive state get activated once they bind with an active module. Initially, only seed modules (one per desired hexagon) are in the active state. The yield of hexagons is greater than in the previous system (as validated by calculation). However, it is not optimal, as multiple seed modules are not prevented from becoming part of a same aggregate.

\section{Breivik's Template-Replicating Polymers}

Breivik [12] developed a system of template-replicating polymers. The system comprises two types of modules A and
B. Modules can bind in two ways. Binding “:” forms discrete pairs between single A and single B modules $(A: B)$, whereas binding "-" forms continuous polymers of arbitrary sequence $(-A-B-B-A-B-)$. Binding “:” is more probable and less stable than binding " - " is. The bindings are implemented using permanent magnets of different Curie points (i.e., the temperature above which the characteristic ferromagnetic ability disappears). The module's logic is coded in hardware (i.e., in the particular shape and binding mechanism). The basic concept is further detailed in [13], where it is extended to systems in which the modules "comprise a self-propelling motor unit."

In an experiment, 70 modules (35 of each type) floated freely in an agitated liquid two-dimensional (2-D) environment. The ambient temperature was subject to change to temporarily exceed the Curie points of the 
magnets. Through repetitive thermocycles, "polymers formed and acted as templates for the formation of new sequences" [see Fig. 2(b)].

\section{White et al.'s Self-Assembling Programmable Modules}

White et al. studied two systems in which the module's binding preferences are coded in a program executed by an on-board microcontroller, and thus can easily change in time [111]. The modules float passively on an air table that is fixed to an orbital shaker. In the first system, each module is of cuboid shape and can connect to other modules on four of its faces [see Fig. 2(c)]. The binding mechanisms are switchable electromagnets. In the second system, modules are of triangular shape and equipped with swiveling permanent magnets [see Fig. 2(d)]. The basic modules are unpowered. Once they bind with a seed module that is connected to a power supply, they become active.

The systems displayed self-reconfiguring entities, that is, modular entities that change structure, in this case, by having modules disband and reunite at different places. Both systems demonstrated self-assembly and subsequent self-reconfiguration with three modules. Using the first system, further experiments were carried out to determine the mean time until the first binding occurs in an environment with either two or three modules.

The authors consider an analytical model, which suggests that the number of modules in an entity increases quadratically in time, if the growth is unconstrained. A simple computational model of the physical system is presented. It confirms the quadratic order for the unconstrained growth for two different module densities (provided that a sufficient number of modules are available). If modules are programmed to self-assemble into structures of specific shapes, the growth rate largely depends on the particular algorithm used.

\section{E. Griffith et al.'s Electromechanical Assemblers}

Griffith et al. studied a system of template-replicating polymers [43], [44]. In the initial designs [44], the system comprises two distinct types of modules (as in the system of Breivik). In the final design, all modules are of a same type but are programmable and can store distinct states. The modules slide passively on an air table. Each module has two active and two passive binding sides [see Fig. 2(e)]. Each active side is equipped with a physical latch that is activated by an electromagnet once a mating module is sufficiently close.

The system demonstrated the self-replication of a fivemodule polymer (each module coding 1 bit of information). Each module executed a finite-state machine. In principle, the system could replicate $n$-bit polymers (for arbitrary $n$ ). In addition, passive aggregation (i.e., a process by which components stick irreversibly upon random encounter) was demonstrated with up to 39 free-moving modules. In another experiment, modules self-assembled into a rect- angular structure comprising 30 modules [44]. In this particular experiment, the growth was fairly constrained as the structure did accept new modules to bind only at a single specific position at every moment in time.

\section{F. White et al.'s Systems for Self-Assembly in 3-D}

White et al. developed two modular systems and an apparatus containing an agitated fluid in which modules are subject to random motion in three dimensions (3-D) [110]. In both systems, modules are of cubic shape and with programmable logic. In the first system [see Fig. 2(f)], modules bind to (and disband from) each other using permanent magnets and switchable electromagnets. Selfassembly of two modules was systematically assessed in 50 trials. One module was manually attached to a magnetic plate and thereby connected to an external power supply. The other module could freely move within the apparatus. In $24 \%$ of the trials, the modules self-assembled and subsequently self-reconfigured by disconnecting from each other and reassembling into a configuration that was different from the initial one. Communication among connected modules was used to synchronize the actions required for disconnecting. In addition, passive aggregation was demonstrated with up to four free-moving unpowered modules.

In the second system [see Fig. $2(\mathrm{~g})]$, the fluid of the apparatus flows through pipelines that are integrated in the modules. Six pipelines - one for each face - join in the module's center. Each pipeline is equipped with a valve that can be opened or closed to control the flow. The authors demonstrated the ability of two modules to form and change configuration by self-assembly. One module was fixed to the apparatus, and a pump was connected to the opening of one face. The force of the fluid was directed towards the module and let another module approach and bind with the previous one. There was no binding force other than the pressure caused by the flow of the fluid.

\section{G. Programmable Parts Testbed (PPT)}

Bishop et al. [7] addressed the problem of controlling a system of programmable modules to form nontrivial target structures. The modules slide passively on an air table. Their layout is an equilateral triangle [see Fig. 2(h)]. Each side is equipped with a binding mechanism comprising one fixed and two movable permanent magnets. Power is provided onboard. Once a connection is established, modules exchange information on their state and decide whether to remain bound or to detach. The logic is coded in a graph grammar, which is stored on and interpreted by each module.

Equipped with an adequate grammar, $N$ modules can assemble up to $\lfloor N / 6\rfloor$ hexagons autonomously. Experiments were performed with $N=6$ modules. Klavins et al. [64], [65] examine the problems i) of designing a grammar that causes modules to assemble into desired products, ii) of predicting the time complexity of such processes, and iii) of predicting (and optimizing) the yield of such processes. 


\section{H. Bhalla and Bentley's Self-Assembling Special Purpose Modules}

Bhalla and Bentley [5] studied self-assembly for the formation of objects of predefined shape. A module can have an arbitrary concave and/or convex polygon shape and a single magnetic disk (of arbitrary polarity) attached to an arbitrary position. The modules are specifically designed to assemble an entity of predefined shape. Typically, some modules are interchangeable, that is, their design is identical. During experimentation, the modules reside on a tray that is subject to agitation.

Five systems producing five distinct target shapes were constructed [e.g., see Fig. 2(i)]. In [5], the authors discuss an automated design approach based on artificial evolution.

\section{SELF-ASSEMBLY OF SELF-PROPELLED COMPONENTS}

In this section, we focus on systems with self-propelled components. In these systems, external agitation apparatuses are not required. In nature and technology, selfpropelled components are observed in many systems at the macroscopic scale.

In general, two types of modular systems exist in which self-propelled components assemble:

1) Systems in which each module is self-propelled, and thus can be a component that approaches and assembles with other components. In these systems, modules can be considered mobile robots.

2) Systems in which individual modules have no or highly limited motion abilities. Even though individual modules cannot move, entities comprising multiple assembled modules can fall into the self-propelled category-for instance, if the modules can change their position or orientation with respect to each other. In these systems, modular entities can be considered modular reconfigurable robots [88], [98], [122], [126].

In some systems, modules both with and without selfpropulsion coexist.

\section{A. Reproductive Sequence Device (RSD)}

Half a century ago, Jacobson [60] designed a physical model of self-replication called Reproductive Sequence Device One (RSD I). RSD I is composed of two types of modules, called heads and tails [see Fig. 3(a)]. The modules move autonomously on a circular "railway" track with several sidings. Initially, the modules are arranged in random sequence on the circular track. With the help of an operator, a seed object composed of a head module and a tail module assembles in a siding of the track. A reliable connection is established as the tail module keeps on pushing towards the halted head module. The seed object triggers another pair of head and tail modules to assemble into an identical object on an adjacent siding. This process continues until the system resources (i.e., modules or sidings) get exhausted.

The system proved capable of correctly replicating the seed object in three adjacent sidings [60]. The system operated without human intervention (once the seed was available). In RSD I, only a single, specific template can be replicated. However, reprogramming one of the head modules (that is, changing its punched card) can cause a pair of another head module and a tail module to assemble in the reverse order; the resulting object is unable to replicate.

\section{B. CEBOT}

Fukuda et al. proposed the concept of modular reconfigurable robotics and realized the first implementation with CEBOT [30], [36]. CEBOT is a heterogeneous system composed of modules with different functions (e.g., move, bend, rotate, and slide). A series of prototypes have been implemented. The first prototype, the CEBOT Mark I [31], [32], is of cuboid shape with active and passive connectors on opposite sides. A shape memory alloy (SMA) actuator can cause a latch to catch a lateral groove in a pin from the mating module. It was shown that a module (equipped with two motorized wheels) could approach the back of another module [31], [32]. However, such a "rough approach" was found ineffective for coupling the two modules, as the binding mechanism required a precise alignment. In CEBOT Mark II [29], [33], [34] [see Fig. 3(b)] and CEBOT Mark IV [35], [38] [see Fig. 3(d)], a mechanical hook is used instead for connecting. Additionally, a cone-shaped part fixed on the front of each module matches a counterpart fixed on the back of each module to facilitate alignment during approach. In CEBOT Mark III [37], modules have a hexagonal shape [see Fig. 3(c)]. The six faces are provided with three active and three passive connectors. The binding mechanism is similar to the one employed in CEBOT Mark I. The pins of the active connectors are made of elastic material. The module is equipped with six nozzles providing propulsion on flat terrain.

Fukuda et al. demonstrated the successful docking of a mobile module with a stationary module using the CEBOT Mark II [34], Mark III [37] and Mark IV [38] platforms. In each experiment, the modules were placed at a specific position (at distances up to $60 \mathrm{~cm}$ and at angular displacements of up to $25^{\circ}$ ). Coordination was achieved by making use of a set of infrared detectors and emitters. Communication among the (connected) modules of a modular robot was studied to enable it to approach and connect with an additional module [29].

\section{Bererton and Khosla's System for Cooperative Repair}

Bererton and Khosla studied cooperative repair in a team of two autonomous, wheeled modules [3], [4]. Although the modules cannot establish a firm connection 


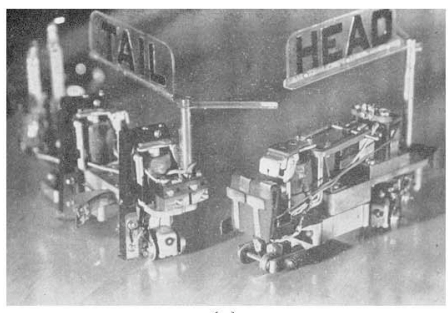

(a)

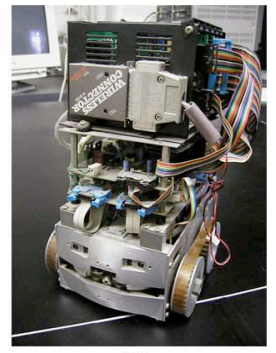

(d)

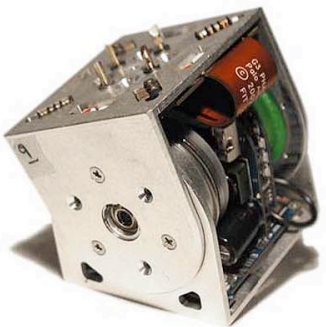

(g)

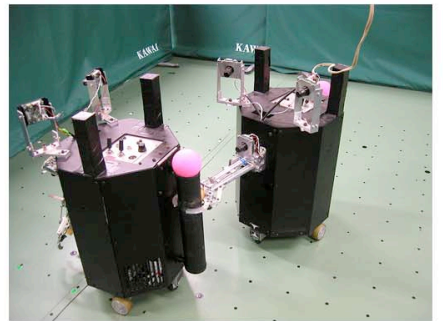

(j)

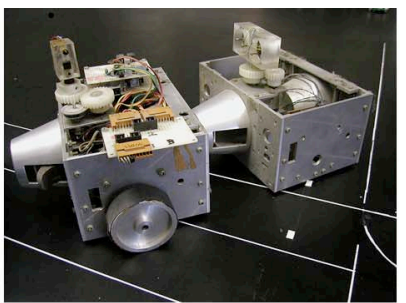

(b)
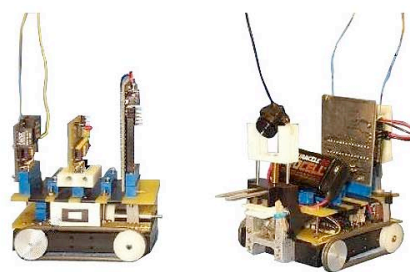

(e)

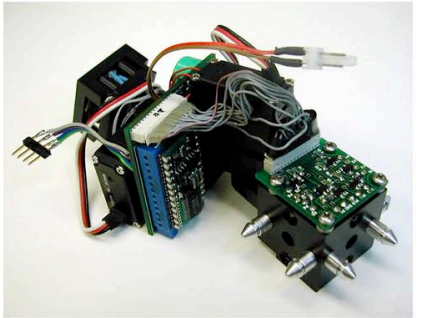

(h)

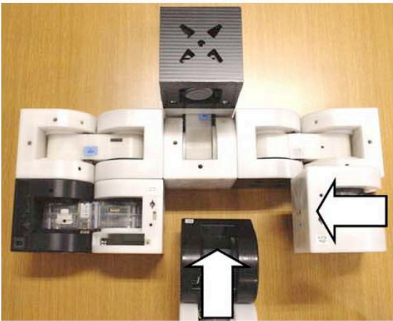

(k)

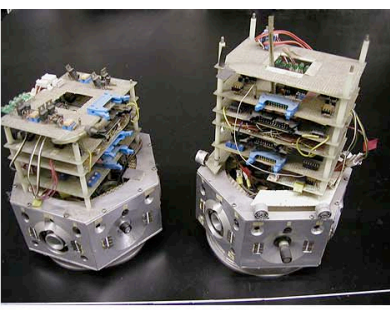

(c)

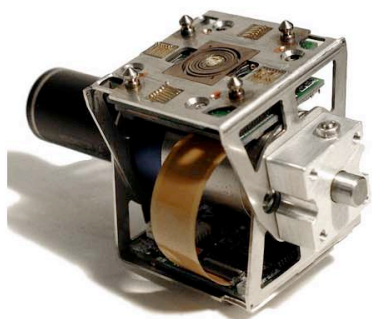

(f)

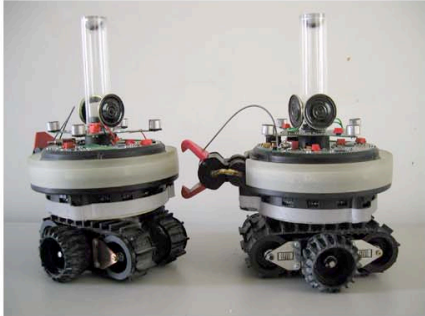

(i)

Fig. 3. Systems with self-propelled components: (a) RSD I (reprinted by permission from Sigma Xi: American Scientist [60]).

(b) CEBOT Mark II. (c) CEBOT Mark III. (d) CEBOT Mark IV. (e) Bererton and Khosla's system for cooperative repair (photo courtesy of C. Bererton and P. K. Khosla, Carnegie Mellon University). (f), (g) PolyBot G2 and PolyBot G3 (courtesy of Palo Alto Research Center, Inc., photographer Rebecca Hinden). (h) CONRO (photo courtesy of P. Will, Information Sciences Institute, University of Southern California). (i) Swarm-bot. (j) Super Mechano Colony. (k) M-TRAN III (photo courtesy of AIST and Tokyo Institute of Technology).

with each other, the difficulties encountered in this study are very similar to those encountered in self-assembly experimentation. One module (the repair robot) is equipped with a forklift mechanism that can be inserted into a receptacle of a defective component of its (stationary) teammate [see Fig. 3(e)]. A black and white camera is mounted on top of the approaching module. It is connected to an external PC that processes the images and sends control commands to the approaching module via a radio-frequency link.

In an experiment reported in [4], a simple state machine proved capable of controlling the repair robot to replace a part of its teammate. In total, 31 trials were conducted "to determine the initial configurations from which the repair robot could successfully dock with the failed robot." The docking was successful for distances of up to $30 \mathrm{~cm}$ and for angular displacements of up to $30^{\circ}$.

\section{PolyBot}

PolyBot [118]-[120], [122], [128] is a chain-based reconfigurable robot that can configure its shape with no external mechanical assistance. Each module has one degree of freedom involving rotation of two opposite binding plates within $a+/-90^{\circ}$ range. Fig. 3(f) shows a 
module of prototype PolyBot G2. An SMA actuator integrated in each binding plate can rotate a latch to catch lateral grooves in the pins from the mating binding plate. Additional passive cuboid segments with six binding plates can be used to introduce branches to the structure and to connect with an (external) power supply. Active modules are equipped with infrared (IR) detectors and emitters integrated in the binding plates.

Yim et al. [124] demonstrated the ability of a modular robot arm composed of six PolyBot G2 modules to approach and grasp another module on flat terrain. One end of this arm was attached to a wall of the arena. To let the other end reach a predetermined position near the target module, the joint angles for each segment were calculated by an inverse kinematics routine. Following on from this, further alignment and approach were supported by making use of the IR detectors and emitters and, finally, by the mechanical properties of the binding mechanism (pins sliding into chamfered holes). A similar experiment was accomplished using PolyBot G3 modules [120], [124], [128] [see Fig. 3(g)]. A modular arm composed of seven modules approached and docked with another module [116]. One end of this arm was attached to the ground. The other end could operate in 3-D. In the experiment, the arm and the target module were set up approximately in a same vertical plane.

\section{E. CONRO}

CONRO is a homogeneous, chain-based reconfigurable robot [17], [18], [89]. Each module comprises a processor, power supply, sensors, and actuators [see Fig. 3(h)]. The basic implementation consists of three segments connected in sequence: a passive connector, a body, and an active connector. The connectors can be rotated with respect to the body in the pitch and yaw axes by means of two motorized joints. An SMA actuator integrated in the active connector can rotate a latch to catch lateral grooves in the pins from the plate of the mating passive connector. IR emitters and detectors are integrated in the binding plates to support the docking and to enable communication between connected modules.

Shen and Will [100] conducted experiments where a chain of seven linearly linked CONRO modules connects into a ring by self-docking. The basic three-stage strategy, originally proposed in [18], can also be found in the experiments with PolyBot (see Section III-D). Rubenstein et al. [97] demonstrated the ability of two separate CONRO robots to self-assemble. Each robot consisted of a chain of two linearly linked CONRO modules. To ensure that both chains perceive each other, they were set up at distances of not more than $15 \mathrm{~cm}$, facing each other with an angular displacement not larger than $45^{\circ}$. The control was heterogeneous, both at the level of individual modules within each robot and at the level of the modular makeup of both robots. In an experiment, the two modular robots successfully self-assembled in ten out of ten trials. The robots were tethered to an external power supply.

\section{F. Swarm-Bot}

Swarm-bot [23], [24], [72], [73] is a homogeneous modular robotic system. Each module has a combination of tracks and external wheels, called treels [see Fig. 3(i)]. It has a gripper that is mounted on an elevation arm. The module can receive connections on more than two-thirds of its perimeter. The mechanical design of the gripper and the connection ring helps the modules to align passively during the grasping phase. For the purpose of intermodule communication, the module has eight RGB light-emitting diodes. The module is equipped with a variety of sensors, including 19 proximity sensors, two optical barriers integrated in the gripper, a VGA omnidirectional camera, and four omnidirectional microphones.

Groß and Dorigo [47] developed a hybrid controller, combining the activation mechanism proposed by Hosokawa et al. [57] with a neural network for motion control. The performance of the system was systematically assessed under a variety of conditions [45], [46]. In each of 220 trials, a single module, controlled to connect with a nonmoving seed object, successfully connected. In 34 trials with six modules and one seed object, $98 \%$ of the modules successfully connected to the seed structure while the other $2 \%$ failed. Self-assembly was also systematically examined on different types of rough terrain. The system performance scaled well with the number of modules, as experimentally verified with groups of 16 modules (and up to 100 modules in simulation). Given a high density of modules in the environment, it was shown in simulation that the mean time until a module connects to a growing entity increases sublinearly with the group size. Groß et al. [46] demonstrated the ability of seven modules to make use of self-assembly in order to cross a hole that cannot be overcome by less than three modules (whether assembled or not). O'Grady et al. [87] conducted a systematic experiment showing that groups of up to three modules can benefit from making adaptive use of self-assembly in all-terrain navigation. If possible, the modules navigated independently. If, however, the terrain proved too difficult for a single module, the group self-assembled into a larger entity and collectively navigated the terrain. Further experiments with up to 18 modules confirm the usefulness of self-assembly in the transport of heavy objects [51], [72], [84], [108].

\section{G. Super Mechano Colony (SMC)}

Super mechano colony (SMC) [21], [54], [55] is a modular robotic concept composed of a parent module and several child modules attached to it. Child modules are an integral part of the system's locomotion. In addition, the child modules can disband to accomplish separate, autonomous missions and reconnect once the missions are accomplished. Hirose et al. [21], [55] introduced an early prototype of the SMC concept. Two motorized and two passive wheels provide mobility on flat terrain. Each module is equipped with a manipulation arm that can be 
elevated and a gripper attached to it. The upper body (including the gripper) can be rotated with respect to the chassis by means of a motorized vertical axis.

Groß et al. [50] ported a control algorithm for selfassembly from the swarm-bot platform to a prototype of the SMC platform. Although there are substantial differences between the two systems, it was shown that it is possible to reproduce qualitatively the basic functionality of the source platform on the target platform. Groß et al. showed that the ported controller was capable of letting a child module assemble with another child module for approaching angles of up to $150^{\circ}$ [see Fig. 3(j)]. In 91 out of 92 trials, the modules correctly established a connection. Another experiment was carried out to investigate the controlled formation of distinct structures in a group of four child modules.

\section{H. M-TRAN}

M-TRAN [62], [79], [125] is a homogeneous modular robotic system in which modules reside in chain and lattice structures. Each module comprises two semicylindrical blocks and a link connecting them. The blocks can rotate within $\mathrm{a}+/-90^{\circ}$ range around two parallel axes. One block of the module has three active surfaces for connecting, the other block has three passive ones.

Using the M-TRAN III platform, Murata et al. [75] demonstrated the docking of a mobile modular robot (composed of three modules) with a stationary modular robot. The docking was supported by sensory feedback from a dedicated camera module mounted on the stationary robot. Both image processing and control were performed on an external PC that communicated wirelessly with the modules. To achieve an accurate alignment in the final approach phase, the stationary robot clutched the connecting module of the approaching robot [see Fig. 3(k)]. The procedure proved successful for a variety of initial positions and orientations. Moreover, an integrated sequence comprising both self-assembly and self-reconfiguration was demonstrated with 18 modules in total [75]. Thereby, the entity that assembled changed shape by having modules move within its structure.

\section{TAXONOMY AND DESIGN PRINCIPLES}

In the following, we classify the information gathered in Sections II and III to help understand the relations among the different systems and to extract some underlying design principles. The section is organized into four parts with focus, respectively, on physical and electrical design characteristics, outcome and analysis of self-assembly experimentation, process control, and functionality.

\section{A. Physical and Electrical Design Characteristics}

In total, we have identified 21 different modular systems capable of self-assembly at the macroscopic scale.
The Appendix of this paper details the physical and electrical characteristics of the modules, including their size, weight, number of degrees of freedom (DOF), and binding mechanism, as well as on-board equipment such as batteries, processors, sensors, and communication devices.

Overall, a diverse set of systems has been implemented, with modules ranging from a few centimeters to half a meter, and from 4 to $11000 \mathrm{~g}$. The design of a module layout is a highly sophisticated task. Typically, it incorporates an enormous amount of human intelligence. Automated design procedures [5], [70] have not yet been investigated in much detail.

Most systems are homogeneous, that is, all modules are identical in design. Modules of distinct types (if any) typically are complementary in terms of their binding mechanisms or functionalities. The number of distinct types of modules is low (whenever distinct types exist). This could help the fabrication of large quantities of modules. In most systems, however, the fabrication process still requires a considerable amount of human intervention. In addition, the process does not yield multiple modules in parallel.

The modules implement a wide range of binding mechanisms, making use of mechanics (with active or passive interlocking), magnetism, impulse, friction, and pressure. All binding mechanisms impose limits on the force that can be transmitted between assembled modules. They also impose limits on the relative positions under which modules can bind to each other. This in turn may limit the type of structures that can be formed. In most systems, the design of the modules (i.e., their connecting faces) helps them to align passively upon collision. This strategy may not always be applicable, for example, if the approaching components are modular entities that are both large and rigid. However, the design of such modular entities (i.e., their morphology) can facilitate passive alignment as well. For a further discussion of desired properties of binding mechanisms, see [83].

Communication can take place in two distinct situations: between separate modules or modular entities and within a modular entity. Communication between separate entities (if any) is local unless dedicated global communication channels are available. Communication within a modular entity can take place through serial or parallel links among all the connected modules.

1) Systems With Externally Propelled Components: In systems with externally propelled components, modules encounter each other at random. The modules are designed to operate in a limited range of (potentially unstructured) environments. The environment imposes constraints on the design; for instance, a module's motion can be affected by its buoyant, frictional, and gravitational forces. Some researchers report difficulties in implementing random motion without any bias in direction [7], [110].

In the system of Griffith et al. and in PPT, modules are equipped with on-board batteries. Therefore, in principle, any 
two modules can bind and communicate with each other upon encounter. In White et al.'s systems, modules are unpowered by default. A special seed module is directly linked to an external power supply; modules that bind with the seed structure receive power through the connection link.

Computing requirements for externally propelled modules are relatively low: in all the systems that we identified, modules can bind passively upon collision, and if any computation is necessary, it reflects the decision whether to stay assembled or not.

2) Systems With Self-Propelled Components: At the level of individual modules, propulsion can be realized with a differential drive, which provides good steering abilities on flat terrain. Tracks on the other hand allow for good allterrain navigation. Modules of swarm-bot combine these two locomotion mechanisms to achieve good mobility on both flat and rough terrain. Modules of CEBOT Mark III have nozzles providing propulsion on flat terrain. At the level of modular entities, propulsion requires more elaborate strategies. This is merely due to the high number of DOFs that need to be controlled in a coordinated and often distributed manner and to the imprecision in actuation that results in positional errors, which increase with the number of elements in sequence.

In some systems with self-propelled modular entities, the latter can change shape by having modules move within their entity. This capacity is called shape-change-a special case of self-reconfiguration-and is typically performed very well by modular reconfigurable robots, such as CONRO, PolyBot, and M-TRAN. Modules of these systems could assemble an arbitrary initial structure and subsequently customize it by shape-changing.

Modules of most systems (in particular, those of modular reconfigurable robots) have a high power consumption, which limits their lifetime without external power supply. They typically i) perceive each other and/or the environment and ii) act to selectively encounter each other. This can put great demands on a module's design. In fact, many problems encountered in the design of selfassembling systems are due to shortcomings in the underlying hardware, such as the modules' actuation [31], [56], [82], perception [15], [56], [74], [124], [130], and computational resources [4], [15], [56], [74].

\section{B. Outcome and Analysis of Self-Assembly Experimentation}

Self-assembly of separate macroscopic components has been demonstrated for 21 different systems. Table 1 provides an overview of the experiments that were performed. Details on the experimental setup and results can be obtained from the references listed in the first column of the table. The second column refers to the figure that shows component modules of the corresponding system.

Most of the experiments were carried out in simple environments in which motion is restricted to either one dimension (1-D) or 2-D (see the third column of Table 1). PolyBot [116], the systems of White et al. [110], and swarm-bot represent initial attempts to study self-assembly in more complex situations, such as 3-D environments, high-density environments, and rough terrain.

Most experiments were conducted as proofs of concept. While the number of components has been large in simulation, physical systems rarely comprised more than 50 modules, and typically no more than two components self-assembled into a same entity. For eight out of 21 systems, the self-assembly process was systematically examined using quantitative performance measures and performing multiple trials. To the best of our knowledge, Hosokawa et al.'s system and swarm-bot are the only systems for which self-assembly of more than two discrete components has been systematically examined. Hosokawa et al. analyzed the yield of desired products as well as the process dynamics (with six discrete components per entity). In the swarm-bot system, the analysis addressed the reliability and speed by which individual modules connect into single entities, as well as the additional capabilities and functions such processes may provide (with up to 16 discrete components per entity).

\section{Process Control}

The process of self-assembly is governed by the modules' way to encounter each other and by the spatially anisotropic binding preferences. In relatively simple systems, modules are externally propelled and have static binding preferences. This is the case for the systems of Hosokawa et al. and of Bhalla and Bentley. In all other systems, a module's motion and/or binding preferences can depend on its state (see column 4 of Table 1). The state can change in response to interactions with other modules and/or the environment. In the system of Penrose, for instance, a module's state changes by mechanical interactions with other modules. In the system of Breivik, a module's state can be affected by the temperature of the environment. In the swarm-bot system, a module's state can depend on the connectivity of other modules in its vicinity.

In 16 out of 21 systems, self-assembly is seeded by a dedicated component (see column 5 of Table 1). All additional products are formed by having components interact with the seed entity and/or the products of such interactions. The seed can be a single module or a modular entity; it can be static or mobile. Typically, the seed is explicitly defined by the experimenter. However, systems can also choose autonomously the components by which to seed the process [87]. Among systems with self-propelled components, only CONRO demonstrated self-assembly without any seed component.

Seven out of 21 systems were autonomous in perception, control, action, and power (see column 6 of Table 1). In most systems, each module executes a deterministic finite-state machine. The logic can be coded 
Table 1 Self-Assembly and Its Function as Either Demonstrated (D:N) or Systematically Verified in Repeated Trials (S:N). "N" Denotes the Maximum Number of Components That Self-Assembled Into a Single Entity

\begin{tabular}{|c|c|c|c|c|c|c|c|}
\hline $\begin{array}{l}\text { Self-Assembling } \\
\text { System }\end{array}$ & Fig. \# & Environment & States & $\begin{array}{l}\text { Seed } \\
\text { Entity }\end{array}$ & $\begin{array}{l}\text { Auto- } \\
\text { nomy }\end{array}$ & Constraints & Function \\
\hline \multicolumn{8}{|c|}{ EXTERNALLY PROPELLED COMPONENTS } \\
\hline Penrose \& Penrose [93] & 1 & $1-\mathrm{D}$ & $\checkmark$ & $\checkmark$ & $\checkmark$ & - & 1-bit replication (D:2) \\
\hline Hosokawa et al. [57] & 2(a) & 2-D & $-a$ & - & $\checkmark$ & - & formation ( $S: 6$ ) \\
\hline Breivik [12] & 2(b) & 2-D (fluid) & $\checkmark$ & - & $\checkmark$ & $\begin{array}{l}\text { partial regulation } \\
\text { by environment }\end{array}$ & growth \& replication (D:16) \\
\hline \multirow[t]{2}{*}{ White et al. [111] } & 2(c) & 2-D & - & $\checkmark$ & - & - & growth (S:2) \\
\hline & & 2-D & $\checkmark$ & $\checkmark$ & - & - & growth \& reconfiguration (D:3) \\
\hline White et al. [111] & $2(d)$ & 2-D & $\checkmark$ & $\checkmark$ & - & - & growth \& reconfiguration (D:3) \\
\hline Griffith et al. [43], [44] & 2(e) & 2-D & $\checkmark$ & $\checkmark$ & $\checkmark$ & - & $\begin{array}{l}\text { growth (D:30), } \\
\text { 5-bit replication (D:5) }\end{array}$ \\
\hline White et al. [110] & $2(\mathrm{f})$ & 3-D (fluid) & $\checkmark$ & $\checkmark$ & - & - & growth \& reconfiguration $(\mathrm{S}: 2)$ \\
\hline White et al. [110] & $2(\mathrm{~g})$ & 3-D (fluid) & $\checkmark$ & $\checkmark$ & - & - & growth \& reconfiguration (D:2) \\
\hline PPT [7] & 2(h) & 2-D & $\checkmark$ & - & $\checkmark$ & - & formation (D:6) \\
\hline Bhalla \& Bentley [5] & $2(\mathrm{i})$ & 2-D & - & - & $\checkmark$ & - & formation (D:10) \\
\hline \multicolumn{8}{|c|}{ SELF-PROPELled COMPONENTS } \\
\hline RSD I [60] & $3(a)$ & $\begin{array}{l}\text { 1-D } \\
\text { (loop \& } \\
\text { branches) }\end{array}$ & $\checkmark$ & $\checkmark$ & - & $\begin{array}{l}\text { partial regulation } \\
\text { by environment }\end{array}$ & replication (D:2) \\
\hline CEBOT, Mark II [34] & 3(b) & 2-D & $\checkmark$ & $\checkmark$ & - & - & growth (D:2) \\
\hline CEBOT, Mark III [37] & $3(\mathrm{c})$ & 2-D & $\checkmark$ & $\checkmark$ & - & - & growth (D:2) \\
\hline CEBOT, Mark IV [38] & $3(d)$ & 2-D & $\checkmark$ & $\checkmark$ & - & - & growth (D:2) \\
\hline Bererton \& Khosla [4] & $3(\mathrm{e})$ & 2-D & $\checkmark$ & $\checkmark$ & - & limited approaching angle & sub-module repair $(\mathrm{S}: 2)$ \\
\hline PolyBot, G2 [124] & $3(f)$ & 2-D & $\checkmark$ & $\checkmark$ & - & pre-defined positions & growth (D:2) \\
\hline $\begin{array}{l}\text { PolyBot, G3 [116], } \\
\text { [124] }\end{array}$ & $3(\mathrm{~g})$ & $3-\mathrm{D}^{b}$ & $\checkmark$ & $\checkmark$ & - & pre-defined positions & growth (D:2) \\
\hline CONRO [97] & $3(\mathrm{~h})$ & 2-D & $\checkmark$ & - & $-c$ & limited approaching angle & growth (S:2) \\
\hline $\begin{array}{l}\text { Swarm-bot [46], [51], } \\
\text { [87] }\end{array}$ & $3(\mathrm{i})$ & $\begin{array}{l}\text { 2-D (flat \& } \\
\text { rough) }\end{array}$ & $\checkmark$ & $\checkmark$ & $\checkmark$ & $\begin{array}{l}\text { limited approaching } \\
\text { angle }^{d}\end{array}$ & $\begin{array}{l}\text { growth (S:16), task-oriented } \\
\text { growth (D:7, S:4) }\end{array}$ \\
\hline SMC [50] & $3(\mathrm{j})$ & 2-D & $\checkmark$ & $\checkmark$ & $-c$ & limited approaching angle & $\begin{array}{l}\text { growth (S:2, D:4), } \\
\text { formation (D:4) }\end{array}$ \\
\hline M-TRAN III [75] & $3(\mathrm{k})$ & 2-D & $\checkmark$ & $\checkmark$ & - & limited approaching angle & growth \& reconfiguration $(\mathrm{S}: 2)$ \\
\hline
\end{tabular}

in hardware, as in the system of Penrose, RSD I, and the system of Breivik, or in software, as in all other statebased systems. In PPT, for instance, each module executes a program that interprets a graph grammar defining state-dependent binding preferences. For the swarm-bot system, evolutionary algorithms have been applied to automate the control design. Attempts to port a controller from one physical system to another are still rare and typically require the platforms to share some common properties.

For some systems, self-assembly has been reported to take place under constrained conditions (see column 7 of Table 1). In the PolyBot systems, for example, components have a priori knowledge of their relative starting positions. We include these systems in our paper as a border line case, as the a priori knowledge was only exploited to get 
the components into sensing range with each other [124]. On the other hand, we exclude from the survey processes in which components are prearranged in a well-ordered structure - in the sense that their design perfectly matches their particular arrangement (e.g., [130]). In the RSD I system, as noted by Freitas and Merkle [28], "a great deal of functionality essential for replication resides in the environment." We include this system in our paper because the assembly process is substantially regulated by the components themselves (e.g., the decision of which components would assemble was a function of the types of components that interacted during the process). On the other hand, we exclude from this paper those processes that are primarily regulated externally. This is the case, for example, for the works of Suthakorn et al. [104] and Lee et al. [67], where the components are guided by environmental markers and where neither the stimulus of, nor the response to, these markers varies with component type.

\section{Functionality}

The last column of Table 1 details the basic function of the system that was either demonstrated (D:N) or systematically verified in repeated trials $(\mathrm{S}: \mathrm{N})$. Thereby, " $\mathrm{N}$ " indicates the maximum number of separate components that self-assembled into a single entity. Selfassembly can have multiple purposes:

- Formation: production of one or more objects of a predefined size and structure. In some systems, the module layout is specifically designed for the assembly of a specific product (e.g., in the system of Hosokawa et al.). In other systems, the final product is flexible, as it can be defined by reprogramming each module (e.g., in PPT). In the latter category of systems, modules have typically a same simple geometry (e.g., a cube). In general, by controlling properties of the underlying components, one can influence properties of the final product, such as its appearance, cohesion, and feel.

- Growth: increase of the number and/or type of modules in an entity. To some extent, this capacity is available in all self-assembling systems. However, it can be limited by the design. For example, constraints in the mechanical design can limit the maximum size of modular entities as well as the speed and/or reliability of the self-assembly process. Modules of the swarm-bot system have shown to form growing entities that display enhanced group level capabilities and functions. Examples are i) transport of objects too heavy for manipulation by the modules when separate, and ii) locomotion over terrains unnavigable for individual modules. Systems whose capabilities and functions (e.g., strength) scale well with the number of modules are yet to be seen.
- Self-reconfiguration: change of an existing entity's morphology. In general, this capability can be achieved by disassembling and reassembling (e.g., as in the systems of White et al.) or by having modules shape-change, that is, move within a preassembled entity (e.g., as in M-TRAN). Many systems support only one of these reconfiguration modes. In general, self-reconfiguration becomes very important when the system needs to be adaptive. For SMC, for example, Yamakita et al. [114], [115] showed that, by disconnecting and reconnecting into a new configuration, a modular entity could better cope with a new environmental situation. However, as the modules' design matched perfectly the required reconfiguration, we do not consider this process as self-assembly (see also Section IV-C).

- Self-repair: replacement of an entity's defective modules with operational modules. In principle, the operational modules can already reside within the entity (as redundant modules) - for example, see [80] and [127]. Alternatively, the entity can assimilate additional modules from the environment. As pointed out in [80], modules that are homogeneous both in terms of hardware and in terms of software seem best suited for self-repair.

- Template replication: replication of a template by producing objects of identical size, structure, and state. Templates can be, for example, preassembled, specific seed entities (e.g., as in RSD I), preassembled seed entities with information in the modules' state (e.g., as in Penrose's and in Griffith et al.'s systems), or products of the selfassembly process (e.g., as in Breivik's system). Most of the above systems replicate information, where the "memory" to store this information is represented by the template's structure itself. Information can then be copied locally by the formation of complementary pairs. As pointed out by Freitas and Merkle [28, page 82], such method can operate on either 1-D or 2-D templates. They note that "the difficulty in plating-type [i.e., 2-D] replication is in the termination signal, where the copy is to separate from the original to make way for a subsequent round of replication."

\section{ACHIEVEMENTS AND FUTURE DIRECTIONS}

A vast amount of research in various fields has contributed to the study of self-assembling systems. It is beyond the scope of this paper to summarize these contributions. Instead, in Table 2, we list some of the main achievements as demonstrated with concrete systems displaying (physical) self-assembly of macroscopic components. Columns 2 and 3 report on achievements with 
Table 2 Main Achievements in Regard to Systems Displaying (Physical) Self-Assembly of Macroscopic Components

\begin{tabular}{|c|c|c|c|c|}
\hline \multirow[t]{2}{*}{ Achievement } & \multicolumn{2}{|c|}{ EXTERNALLY PROPELLED COMPONENTS } & \multicolumn{2}{|c|}{ SELF-PROPELLED COMPONENTS } \\
\hline & Details & Self-Assembling System & Details & Self-Assembling System \\
\hline $\begin{array}{l}\text { smallest module } \\
(\mathrm{L} / \mathrm{W} / \mathrm{H} \text { in } \mathrm{cm})\end{array}$ & $2.5 \times 2.2 \times 1.0$ & Hosokawa et al. [57] & $5.0 \times 5.0 \times 4.5$ & PolyBot, G3 [120] \\
\hline $\begin{array}{l}\text { biggest module } \\
(\mathrm{L} / \mathrm{W} / \mathrm{H} \text { in } \mathrm{cm})\end{array}$ & $13 \times 13 \times 13$ & White et al. [110] & $26 \times 26 \times 51$ & SMC [21], [50] \\
\hline most capable module & $\begin{array}{l}\text { computing, } \\
\text { communication }\end{array}$ & $\begin{array}{l}\text { White et al. [110], [111], } \\
\text { Griffith et al. [44], } \\
\text { PPT [7] }\end{array}$ & $\begin{array}{l}\text { computing, audio, force, } \\
\text { vision }\end{array}$ & Swarm-bot [72] \\
\hline most modules involved & 100 & Hosokawa et al. [57] & 18 & $\begin{array}{l}\text { Swarm-bot [72], } \\
\text { M-TRAN III [75] }\end{array}$ \\
\hline $\begin{array}{l}\text { most components to form } \\
\text { single entity }\end{array}$ & 30 & Griffith et al. [44] & 16 & Swarm-bot [46] \\
\hline \multirow[t]{2}{*}{ formation } & synthesis & $\begin{array}{l}\text { Hosokawa et al. [57], } \\
\text { PPT [7], [65], } \\
\text { Bhalla \& Bentley [5] }\end{array}$ & synthesis & SMC [50] \\
\hline & $\begin{array}{l}\text { prediction of dynamics } \\
\text { and yield }\end{array}$ & $\begin{array}{l}\text { Hosokawa et al. [57], } \\
\text { PPT [64] }\end{array}$ & & \\
\hline self-reconfiguration & $2-3$ components & White et al. [110], [111] & $\begin{array}{l}2 \text { components assembly } \\
\text { and } 18 \text { module (internal) } \\
\text { reconfiguration }\end{array}$ & M-TRAN III [75] \\
\hline \multirow[t]{3}{*}{ template replication } & 1-bit & Penrose \& Penrose [93] & specific & RSD I [60] \\
\hline & open-ended & Breivik [12] & & \\
\hline & $n$-bit $(n=5$ experiment) & Griffith et al. [43] & & \\
\hline \multirow[t]{3}{*}{ energy autonomy } & unlimited time & $\begin{array}{l}\text { Penrose \& Penrose [93], } \\
\text { Hosokawa et al. [57], } \\
\text { Breivik [12], } \\
\text { Bhalla \& Bentley [5] }\end{array}$ & powered by environment & RSD I [60] \\
\hline & $\begin{array}{l}\text { powered upon connection } \\
\text { to seed structure }\end{array}$ & White et al. [110], [111] & power sharing & PolyBot, G2 \& G3 [120] \\
\hline & $2-4 \mathrm{~h}$ on-board power & $\begin{array}{l}\text { Griffith et al. [44], } \\
\text { PPT [7] }\end{array}$ & $2-3 \mathrm{~h}$ on-board power & $\begin{array}{l}\text { Bererton \& Khosla [4], } \\
\text { Swarm-bot [46], [72] }\end{array}$ \\
\hline \multirow[t]{2}{*}{ miscellaneous } & self-assembly in 3-D & White et al. [110] & self-assembly in 3-D & PolyBot, G3 [116], [124] \\
\hline & & & $\begin{array}{l}\text { all-terrain navigation, } \\
\text { object manipulation }\end{array}$ & $\begin{array}{l}\text { Swarm-bot [46], [87], } \\
{[108]}\end{array}$ \\
\hline
\end{tabular}

systems of externally propelled components, whereas columns 4 and 5 report on achievements with systems of self-propelled components.

During the last 50 years, a variety of self-assembling systems were developed and used to design and analyze processes exhibiting a range of elementary functions. Ongoing work continues the study of such processes and functions, in particular, those of formation [6], [20], [39], [63], [71], growth [49], [85], [86], self-reconfiguration [76], [77], [121], self-repair [117], and template replication [131].

We believe that a unifying theory of self-assembly and a profound understanding of its elementary functions would greatly support the design and study of selfassembling systems. In particular, it could help develop an understanding of the relationship between the logic of
Table 3 Technological and Scientific Areas That Are Likely to Benefit From the Study of Macroscopic Self-Assembly

\begin{tabular}{|lll}
\hline Scale & Enhancing Technology & Understanding Nature \\
\hline macroscopic & $\begin{array}{l}\text { all-terrain navigation [56] } \\
\text { educational tools } \\
\text { search \& rescue [72] }\end{array}$ & $\begin{array}{l}\text { meteorology } \\
\text { plant growth } \\
\text { social insects [106] } \\
\text { self-construction [103] }\end{array}$ \\
& self-repair devices [3] & \\
& space robotics [101] & \\
& under water robotics [109] & \\
& 3-D displays [41] & developmental biology \\
mesoscopic & computation [96] of life [22] \\
drug delivery systems [40] & self-replication [43] \\
& manufacturing [26] & \\
& microelectronics [42] & \\
& smart materials &
\end{tabular}


components on one side and the (dynamic or static) patterns, structures, and functions on the other side. In most of the studies that we presented, the authors could predict the structures in which the components selfassembled. If underlying generic principles are uncovered, rules could be generated for expressing arbitrary patterns, structures, or functions. Some promising first steps have already been taken by the development of compilers [61], [65], [81] that take as input a desired pattern or structure and generate a suitable rule set for a system of components. However, current compilers are limited in the range of patterns, structures, and functions they can process, and they assume a simplistic system model. In a recent work [96], Rothemund explores the

Table 4 Physical Characteristics of Modules for Self-Assembly

\begin{tabular}{|c|c|c|c|c|c|c|}
\hline $\begin{array}{l}\text { Self-Assembling } \\
\text { System }\end{array}$ & Fig. \# & $\begin{array}{l}\text { Single } \\
\text { Module } \\
\text { Type }\end{array}$ & $\begin{array}{l}\text { Dimensions } \\
(\mathrm{L} / \mathrm{W} / \mathrm{H} \\
\text { in } \mathrm{cm})\end{array}$ & $\begin{array}{l}\text { Weight } \\
\text { (in g) }\end{array}$ & $\begin{array}{l}\text { DOF } \\
\text { (Full/Binary) }\end{array}$ & Binding Mechanism \\
\hline \multicolumn{7}{|c|}{ EXTERNALly PROPELLED COMPONENTS } \\
\hline Penrose \& Penrose [93] & 1 & - & $\begin{array}{l}\text { not } \\
\text { specified }\end{array}$ & $\begin{array}{l}\text { not } \\
\text { specified }\end{array}$ & $0 / 0$ & $\begin{array}{l}\text { mechanical interlocking } \\
\text { upon collision }\end{array}$ \\
\hline Hosokawa et al. [57] & 2(a) & $\checkmark$ & $2.5 / 2.2 / 1.0$ & 3.6 & $0 / 0$ & permanent magnets \\
\hline Breivik [12], [13] & $2(b)$ & - & $6.0 / 4.0 / 2.0$ & 30 & $0 / 0$ & permanent magnets $^{a}$ \\
\hline White et al. [111] & $2(\mathrm{c})$ & $\checkmark$ & $6.5 / 6.5 / 6.5$ & 165 & $0 / 4$ & electromagnets \\
\hline White et al. [111] & $2(d)$ & $\checkmark$ & $6.5 / 6.5 / 6.5$ & 165 & $0 / 3$ & swiveling permanent magnets \\
\hline Griffith et al. [43], [44] & 2(e) & $\checkmark$ & $5.0 / 5.0 / 1.5$ & 26 & $0 / 2$ & $\begin{array}{l}\text { mechanical latch, regulated } \\
\text { electromagnetically }\end{array}$ \\
\hline White et al. [110] & $2(\mathrm{f})$ & $\checkmark$ & $10 / 10 / 10$ & 895 & $0 / 6$ & $\begin{array}{l}\text { electromagnets and permanent } \\
\text { magnets }\end{array}$ \\
\hline White et al. [110] & $2(\mathrm{~g})$ & $\checkmark$ & $13 / 13 / 13$ & 1480 & $0 / 6$ & $\begin{array}{l}\text { pressure of fluid flow, } \\
\text { regulated by valves }\end{array}$ \\
\hline PPT [7] & $2(\mathrm{~h})$ & $\checkmark$ & $12 / 10 / 4.2$ & 110 & $0 / 3$ & swiveling permanent magnets \\
\hline Bhalla \& Bentley [5] & 2(i) & - & $\begin{array}{l}\text { module } \\
\text { specific }\end{array}$ & $\begin{array}{l}\text { module } \\
\text { specific }\end{array}$ & $0 / 0$ & permanent magnets \\
\hline \multicolumn{7}{|c|}{ SElF-PRopelled Components } \\
\hline RSD I [60] & $3(a)$ & - & $14 / 3.6 / 11$ & $\begin{array}{l}\text { not } \\
\text { specified }\end{array}$ & $1 / 0$ & impulse \& friction \\
\hline $\begin{array}{l}\text { CEBOT, Mark II [36, } \\
\text { pp. 50-56, 151-156], } \\
{[29]}\end{array}$ & $3(\mathrm{~b})$ & - & $13 / 18 / 9.0$ & 2700 & $2-4 / 0$ & actuated mechanical hook \\
\hline CEBOT, Mark III [37] & $3(\mathrm{c})$ & $\checkmark$ & $\begin{array}{l}\text { not } \\
\text { specified }\end{array}$ & $\begin{array}{l}\text { not } \\
\text { specified }\end{array}$ & $0 / 9$ & mechanical pin/hole \& SMA \\
\hline $\begin{array}{l}\text { CEBOT, Mark IV [35], } \\
\text { [38] }\end{array}$ & $3(d)$ & - & $19 / 11 / 24$ & 4100 & $2-3 / 0$ & actuated mechanical hook \\
\hline $\begin{array}{l}\text { Bererton \& Khosla [3], } \\
{[4]}\end{array}$ & $3(e)$ & $\checkmark$ & $10 / 6.0 / 8.0$ & $\approx 250$ & $3 / 0$ & mechanical pin/hole \\
\hline $\begin{array}{l}\text { PolyBot, G2 [119], } \\
{[124]}\end{array}$ & $3(\mathrm{f})$ & - & $6.0 / 7.0 / 11$ & 416 & $1 / 2$ & mechanical pin/hole \& SMA \\
\hline $\begin{array}{l}\text { PolyBot, G3 [120], } \\
{[124],[128]}\end{array}$ & $3(\mathrm{~g})$ & - & $5.0 / 5.0 / 4.5$ & 200 & $1 / 2$ & mechanical pin/hole \& SMA \\
\hline $\begin{array}{l}\text { CONRO [17], [89], } \\
{[97]}\end{array}$ & $3(\mathrm{~h})$ & $\checkmark$ & $11 / 4.4 / 4.5$ & 114 & $2 / 1$ & mechanical pin/hole \& SMA \\
\hline Swarm-bot [72], [73] & 3(i) & $\checkmark$ & $12 / 12 / 19$ & 700 & $5 / 0$ & actuated mechanical hook \\
\hline SMC [21], [50], [115] & $3(\mathrm{j})$ & - & $26 / 26 / 51$ & 11000 & $5 / 0$ & actuated mechanical hook \\
\hline M-TRAN III [75] & $3(\mathrm{k})$ & $\checkmark$ & $13 / 6.5 / 6.5$ & 420 & $2 / 3$ & actuated mechanical hooks \\
\hline
\end{tabular}


capacity of a system of millimeter-scale components to compute by self-assembly. In fact, assembled structures can be interpreted as computations, and vice versa. Theory might help to predict the range of structures (and functions) a given system can produce, as well as the time complexity to do so.

Macroscopic self-assembly is of wide interest throughout science and technology. Macroscopic systems are increasingly viewed as viable models for the study of processes at any scale [112]. Table 3 gives a broad flavor of potential applications within technical and scientific areas.

Systems with externally propelled components have great prospects at (but are not limited to) the mesoscopic scale. Modules of these systems do not necessarily require complex computation, actuators, and sensors. A range of studies have addressed the design of systems of millimeterscale components for the formation of 2-D arrays, 3-D regular lattices, helixes, electrical networks, and other structures; for example, see [9]-[11], [42], [58], [105], [107], and [129]. Components at this scale can exhibit a similar range of physical interactions as components at the micro- or even nanoscale (e.g., capillary forces, hydrodynamic shear, and minimization of interfacial free energy). One challenge is the transfer of knowledge gained with macroscopic systems to the design of mesoscopic systems in order to obtain structures that provide function and can cope with changes in the environment (e.g., smart materials).

Systems with self-propelled components have great prospects at (but are not limited to) the macroscopic scale. For example, they could play an important role in autonomous robotic missions, such as the exploration of the surface of another planet. Such missions impose high demands on the flexibility and robustness of a system. From today's technology perspective, the component modules of most systems lack advanced on-board power, computing resources, sensors, or communication abilities. These shortcomings limit the practical use of current systems for complex missions in unstructured terrains. A promising direction, in particular with regard to systems at the mesoscopic scale, is the study of novel mechanisms for self-propulsion. Goldstein et al. [41] investigate designs in which modules, by interacting with each other, achieve propulsion even though they have no moving parts. Such systems are also under development in a recent work by Knaian [66]. Other "emergent" self-propulsion mechanisms are investigated, for example, by Farnell et al. [27] and Ishiguro et al. [59].

In general, the advancement of self-assembling systems requires novel thinking in terms of all aspects of the design. Miniaturization would likely require artificial components to use external powering methods, or harvest energy from their environment (e.g., see [102]). In addition, different mechanisms would have to be considered in terms of sensors, actuators, propulsion, control, and communication (e.g., see [95]). Hybrid systems could combine externally propelled components with actuated degrees of freedom. Components could then passively float in the environment and, upon random encounter, bind to each other to form a structure that changes morphology and/or manipulates the environment (e.g., see [26]). Another interesting example of self-assembly is provided by the gradual intertwining of the branches and/or roots of

Table 5 Electrical Characteristics of Modules for Self-Assembly (Only Systems With Externally Propelled Components)

\begin{tabular}{|c|c|c|c|c|c|}
\hline $\begin{array}{l}\text { Self-Assembling } \\
\text { System }\end{array}$ & Fig. \# & $\begin{array}{l}\text { Bat- } \\
\text { teries }\end{array}$ & Processor(s) & Sensors & Communication Devices \\
\hline \multicolumn{6}{|c|}{ EXTERnally PROPELLED COMPONENTS } \\
\hline Penrose \& Penrose [93] & 1 & - & - & - & - \\
\hline Hosokawa et al. [57] & 2(a) & - & - & - & - \\
\hline Breivik [12], [13] & 2(b) & - & - & - & - \\
\hline White et al. [111] & $2(\mathrm{c})$ & - & $\begin{array}{l}\text { 8-bit Basic Stamp II-SX, } \\
50 \mathrm{MHz}\end{array}$ & - & $\begin{array}{l}\text { serial link between } \\
\text { connected modules }\end{array}$ \\
\hline White et al. [111] & $2(d)$ & - & $\begin{array}{l}\text { 8-bit Basic Stamp II, } \\
20 \mathrm{MHz}\end{array}$ & - & $\begin{array}{l}\text { serial link between } \\
\text { connected modules }\end{array}$ \\
\hline Griffith et al. [43], [44] & $2(e)$ & $\checkmark$ & 8-bit ATmega8, $8 \mathrm{MHz}$ & - & $\begin{array}{l}4 \text { wireless electromagnetic } \\
\text { local transmitters, } 1-10 \mathrm{~mm}\end{array}$ \\
\hline White et al. [110] & $2(\mathrm{f})$ & - & $\begin{array}{l}\text { 8-bit Basic Stamp II-SX, } \\
50 \mathrm{MHz}\end{array}$ & - & $\begin{array}{l}\text { serial link between } \\
\text { connected modules }\end{array}$ \\
\hline White et al. [110] & $2(\mathrm{~g})$ & - & $\begin{array}{l}\text { 8-bit Basic Stamp II-SX, } \\
50 \mathrm{MHz}\end{array}$ & - & $\begin{array}{l}\text { serial link between } \\
\text { connected modules }\end{array}$ \\
\hline PPT [7] & $2(\mathrm{~h})$ & $\checkmark$ & 8-bit PIC18F242, 3.6 MHz & 3 infrared detectors & 3 infrared emitters \\
\hline Bhalla \& Bentley [5] & 2(i) & - & - & - & - \\
\hline
\end{tabular}


certain plants that grow in groups. Such self-assembly relies on developmental processes of the participating components. Connectivity potentially provides adaptive value, for instance, to survive harsh condition. Certainly, many more self-assembly processes can be found in nature, and might inspire next generation designs.

\section{CONCLUSION}

During the last 50 years, a variety of systems were designed displaying self-assembly of components at the macroscopic scale. In this paper, we presented an overview of this research. We compared 21 systems with regard to i) the physical and electrical design characteristics of the component modules, ii) the outcome and analysis of selfassembly experimentation, iii) the mechanisms that control the process of self-assembly, and iv) the functionality that is provided. Thereby, we identified principles that are common to the design of such systems. Finally, we summarized some of the main accomplishments and indicated potential directions for future research.

Overall, an impressive diversity of systems have been realized, acting in various types of environments. The systems provide a range of elementary functions such as formation, growth, self-reconfiguration, self-repair, and template replication. To help the reader in further assessing the current state of the art, we have collected a list of video recordings and additional material, available in [48].

Clearly, studies on macroscopic self-assembly are of potential value for a range of fields, including biology, chemistry, manufacturing, material science, microelectronics, physics, robotics, and sociology. The expertise and variety of view points in these fields hold great potential to be explored for the design and study of artificial and natural self-assembling systems.

Table 6 Electrical Characteristics of Modules for Self-Assembly (Only Systems With Self-Propelled Components)

\begin{tabular}{|c|c|c|c|c|c|}
\hline $\begin{array}{l}\text { Self-Assembling } \\
\text { System }\end{array}$ & Fig. \# & $\begin{array}{l}\text { Bat- } \\
\text { teries }\end{array}$ & Processor(s) & Sensors & Communication Devices \\
\hline \multicolumn{6}{|c|}{ SELF-PROPELLED COMPONENTS } \\
\hline RSD I [60] & $3(\mathrm{a})$ & - & relay ( 1 head, 2 tail) & bump switch ( 0 head, 3 tail) & $\begin{array}{l}\text { parallel link between } \\
\text { connected modules }\end{array}$ \\
\hline $\begin{array}{l}\text { CEBOT, Mark II [36, } \\
\text { pp. } 50-56,151-156] \text {, } \\
{[29]}\end{array}$ & $3(b)$ & - & $\begin{array}{l}\text { sub CPU (+ main CPU } \\
\text { off-board) }\end{array}$ & $\begin{array}{l}4 \text { infrared detectors ( } 3 \text { rigid, } \\
1 \text { rotational), } 3 \text { ultrasonic } \\
\text { distance ( } 1 \mathrm{Tx} \text { and } 2 \mathrm{Rx} \text { ) }\end{array}$ & $\begin{array}{l}9 \text { infrared emitters } \\
\text { ( } 8 \text { rigid, } 1 \text { rotational), } \\
\text { parallel link between } \\
\text { connected modules }\end{array}$ \\
\hline CEBOT, Mark III [37] & $3(c)$ & - & $\begin{array}{l}\text { sub CPU (+ main CPU } \\
\text { off-board) }\end{array}$ & $\begin{array}{l}9 \text { infrared detectors, } 6 \text { ultrasonic } \\
\text { distance ( } 3 T x \text { and } 3 R x \text { ) }\end{array}$ & $\begin{array}{l}9 \text { infrared emitters, } \\
\text { link between } \\
\text { connected modules }\end{array}$ \\
\hline $\begin{array}{l}\text { CEBOT, Mark IV [35], } \\
\text { [38] }\end{array}$ & $3(d)$ & - & 16-bit $8086,5-10 \mathrm{MHz}$ & 2 infrared detectors & $\begin{array}{l}2 \text { infrared emitters, } \\
\text { wireless (RS-232C) }\end{array}$ \\
\hline $\begin{array}{l}\text { Bererton \& Khosla [3], } \\
{[4]}\end{array}$ & $3(\mathrm{e})$ & $\checkmark$ & $\begin{array}{l}\text { 8-bit PIC16C73A, } 20 \mathrm{MHz} \\
\text { + off-board }\end{array}$ & $\begin{array}{l}\text { B\&W camera }(320 \times 240) \text {, } \\
\text { bump switch }\end{array}$ & wireless (RF) \\
\hline $\begin{array}{l}\text { PolyBot, G2 [119], } \\
{[124]}\end{array}$ & $3(f)$ & - & $\begin{array}{l}\text { 32-bit PowerPC } 555 \\
\text { (MPC555), } 40 \mathrm{MHz}\end{array}$ & 4 infrared detectors & $\begin{array}{l}8 \text { infrared emitters, } \\
2 \text { CANbus }\end{array}$ \\
\hline $\begin{array}{l}\text { PolyBot, G3 [120], } \\
{[124],[128]}\end{array}$ & $3(\mathrm{~g})$ & - & $\begin{array}{l}\text { 32-bit PowerPC } 555 \\
(\mathrm{MPC} 555), 40 \mathrm{MHz}\end{array}$ & $\begin{array}{l}8 \text { infrared detectors, } 2 \text {-axis } \\
\text { inclinometers, } 81 \text {-axis force }\end{array}$ & $\begin{array}{l}8 \text { infrared emitters, } \\
2 \text { CANbus }\end{array}$ \\
\hline $\begin{array}{l}\text { CONRO [17], [89], } \\
{[97]}\end{array}$ & $3(h)$ & $\checkmark$ & $\begin{array}{l}\text { 8-bit Basic Stamp II-SX, } \\
50 \mathrm{MHz}\end{array}$ & 4 infrared detectors & 4 infrared emitters \\
\hline $\begin{array}{l}\text { Swarm-bot [46], [72], } \\
{[73]}\end{array}$ & 3(i) & $\checkmark$ & $\begin{array}{l}\text { 32-bit XScale, } 400 \mathrm{MHz} \\
\text { + } 138 \text {-bit PIC16F876/7, } \\
20 \mathrm{MHz}\end{array}$ & $\begin{array}{l}19 \text { infrared proximity, } \\
\text { color camera }(640 \times 480 \text {, } \\
\text { omnidirectional), 2-axis force, } \\
\text { torque, } 4 \text { microphones, } 8 \text { light, } \\
3 \text {-axis inclinometer, } 2 \text { humidity, } \\
2 \text { light barriers }\end{array}$ & $\begin{array}{l}8 \text { RGB LEDs changing } \\
\text { body color, } 2 \text { speakers, } \\
\text { Wi-Fi }\end{array}$ \\
\hline SMC [21], [50], [115] & $3(\mathrm{j})$ & $\checkmark$ & $\begin{array}{l}\text { 32-bit Pentium MMX, } \\
233 \mathrm{MHz}\end{array}$ & $\begin{array}{l}\text { color camera ( } 2 \text { per parent: } \\
640 \times 416,2-3 \text { per child: } \\
320 \times 240 \text { ), } 1 \text {-axis force }\end{array}$ & $W i-F i$ \\
\hline M-TRAN III [75] & $3(\mathrm{k})$ & $\checkmark$ & $\begin{array}{l}\text { 32-bit HD64F7047, } 48 \\
\mathrm{MHz}, 316 \text {-bit HD64F3687 } \\
194,16 \mathrm{MHz}+\text { off-board }\end{array}$ & $\begin{array}{l}13 \text { infrared detectors, } 3 \text {-axis } \\
\text { inclinometer }\end{array}$ & $\begin{array}{l}13 \text { infrared emitters, } \\
\text { CANbus, wireless } \\
\text { (BlueTooth) }\end{array}$ \\
\hline
\end{tabular}




\section{APPENDIX I}

Tables 4-6 summarize the physical and electrical characteristics of the modules of the 21 systems discussed in this paper. Entries of the first columns identify each system by its name, if any, or (otherwise) by the name of the authors (abbreviated, if more than two) that reported in the literature on the system's implementation. The second column refers to the figure that shows component modules of the corresponding system. Table entries that are italicized have been obtained directly by contacting one of the authors of the corresponding study. All other entries have been obtained from the references specified in the first columns.

All tables list only the characteristics of standard modules. Additional modules might have been designed for special purposes and could be complementary in functionality. In Table 4, entries of the third column indicate whether or not a system is composed of homogeneous modules. The dimensions (in centimeters) listed in the fourth column specify the length, width, and height of a module excluding its binding mechanism. Typically, it is this measure that is reported in the literature. Entries of the fifth column specify a module's weight (in grams). For systems in which fluid can enter the module, the module's net weight is reported. The sixth column details a module's number of DOFs. DOFs with two displacements only (e.g., a latch) are referred to as binary; all others as full. The last column details the principle of the module's binding mechanism. Tables 5 and 6 present, respectively, the electrical characteristics of modules in systems with externally propelled components and in systems with self-propelled components. Entries of the third column specify whether a module has on-board power or not. The fourth column lists the available on-board processing resources. It is noted if a module was designed for being controlled remotely. The fifth column summarizes a module's on-board sensors. These do not include proprioceptive sensors, nor those sensors integrated only on nonstandard modules. The last column lists a module's devices for intermodule communication. This comprises communication in both the assembled and the separate state.

\section{Acknowledgment}

The authors thank C. A. Bererton, N. Bhalla, M. Bonani, M. Buss, D. Duff, N. R. Franks, T. Fukuda, E. Klavins, H. Kurokawa, H. Lipson, F. Mondada, K. Motomura, S. Murata, M. Rubenstein, M. Saito, K. Sekiyama, A. B. Sendova-Franks, P. J. White, M. Yamakita, M. Yim, Y. Zhang, and V. Zykov for their generous support in providing us with information and/or feedback.

\section{REFERENCES}

[1] A. Abrams and R. Ghrist, "State complexes for metamorphic robots," Int. J. Robot. Res., vol. 23, no. 7-8, pp. 811-826, 2004.

[2] C. Anderson, G. Theraulaz, and J.-L. Deneubourg, "Self-assemblages in insect societies," Insectes Soc., vol. 49, no. 2, pp. 99-110, 2002.

[3] C. Bererton and P. K. Khosla, "Towards a team of robots with reconfiguration and repair capabilities," in Proc. 2001 IEEE Int. Conf. Robot. Autom., Los Alamitos, CA, 2001 vol. 3, pp. 2923-2928.

[4] C. Bererton and P. K. Khosla, "Towards a team of robots with repair capabilities: A visual docking system," in Proc. 7th Int. Symp. Exper. Robot., Berlin, Germany, 2001, vol. 271, pp. 333-342, ser. Lecture Notes in Control and Information Sciences.

[5] N. Bhalla and P. J. Bentley, "Working towards self-assembling robots at all scales," in Proc. 3rd Int. Conf. Auton. Robots Agents, Palmerston North, New Zealand, 2006, pp. 617-622.

[6] N. Bhalla, P. J. Bentley, and C. Jacob, "Mapping virtual self-assembly rules to physical systems," in Proc. 2007 Int. Conf. Unconv. Comput., Frome, U.K., 2007, pp. 167-197.

[7] J. Bishop, S. Burden, E. Klavins, R. Kreisberg, W. Malone, N. Napp, and T. Nguyen, "Programmable parts: A demonstration of the grammatical approach to self-organization," in Proc. 2005 IEEE/RSJ Int. Conf. Intell. Robots Syst., Los Alamitos, CA, 2005, pp. 3684-3691.
[8] M. Boncheva, D. A. Bruzewicz, and G. M. Whitesides, "Millimeter-scale self-assembly and its applications," Pure Appl. Chem., vol. 75, no. 5, pp. 621-630, 2003.

[9] M. Boncheva, D. H. Gracias, H. O. Jacobs, and G. M. Whitesides, "Biomimetic self-assembly of a functional asymmetrical electronic device," Proc. Nat. Acad. Sci. USA, vol. 99, no. 8, pp. 4937-4940, 2002.

[10] N. Bowden, A. Terfort, J. Carbeck, and G. M. Whitesides, "Self-assembly of mesoscale objects into ordered two-dimensional arrays," Science, vol. 276, no. 5310, pp. 233-235, 1997.

[11] T. L. Breen, J. Tien, S. R. J. Oliver, T. Hadzic, and G. M. Whitesides, "Design and self-assembly of open, regular, 3D mesostructures," Science, vol. 284, no. 5416, pp. 948-951, 1999.

[12] J. Breivik, "Self-organization of template-replicating polymers and the spontaneous rise of genetic information," Entropy, vol. 3, no. 4, pp. 273-279, 2001.

[13] J. Breivik, "System which can reversibly reproduce itself," U.S. Patent 6652285 , 2001.

[14] R. Brown, "A brief account of microscopical observations made in the months of June, July and August, 1827, on the particles contained in the pollen of plants; and on the general existence of active molecules in organic and inorganic bodies," Phil. Mag., vol. 4, pp. 161-173, 1828.

[15] H. B. Brown, Jr, J. M. V. Weghe, C. A. Bererton, and P. K. Khosla, "Millibot trains for enhanced mobility," IEEE/ASME Trans. Mechatron., vol. 7, no. 4, pp. 452-461, 2002.

[16] D. L. D. Caspar, "Design principles in organized biological structures," in Principles of Biomolecular Organization, G. E. W. Wolstenholme and

M. O'Connor, Eds. London, U.K.: J. \& A. Churchill, 1966, pp. 7-34.

[17] A. Castano, A. Behar, and P. M. Will, "The Conro modules for reconfigurable robots," IEEE/ASME Trans. Mechatron., vol. 7, no. 4, pp. 403-409, 2002.

[18] A. Castano, W.-M. Shen, and P. M. Will, "CONRO: Towards deployable robots with inter-robots metamorphic capabilities," Auton. Robots, vol. 8, no. 3, pp. 309-324, 2000.

[19] G. S. Chirikjian, "Kinematics of a metamorphic robotic system," in Proc. 1994 IEEE Int. Conf. Robot. Autom., Los Alamitos, CA, 1994, vol. 1, pp. 449-455.

[20] A. L. Christensen, R. O'Grady, and M. Dorigo, "Morphology control in a multirobot system," IEEE Robot. Automat. Mag., vol. 14, no. 4, pp. 18-25, 2007.

[21] R. Damoto, A. Kawakami, and S. Hirose, "Study of super-mechano colony: Concept and basic experimental set-up," Adv. Robot., vol. 15, no. 4, pp. 391-408, 2001.

[22] D. Deamer, S. Singaram, S. Rajamani, V. Kompanichenko, and S. Guggenheim, "Self-assembly processes in the prebiotic environment," Phil. Trans. Roy. Soc. B, vol. 361, no. 1474, pp. 1809-1818, 2006. 
[23] M. Dorigo, V. Trianni, E. Șahin, R. Groß, T. H. Labella, G. Baldassarre, S. Nolfi, J.-L. Deneubourg, F. Mondada, D. Floreano, and L. M. Gambardella, "Evolving self-organizing behaviors for a swarm-bot," Auton. Robots, vol. 17, no. 2-3, pp. 223-245, 2004.

[24] M. Dorigo, E. Tuci, V. Trianni, R. Groß, S. Nouyan, C. Ampatzis, T. H. Labella, R. O'Grady, M. Bonani, and F. Mondada, "SWARM-BOT: Design and implementation of colonies of self-assembling robots," in Computational Intelligence: Principles and Practice, G. Y. Yen and D. B. Fogel, Eds. Los Alamitos, CA: IEEE Computer Society Press, 2006, pp. 103-135.

[25] A. Einstein, "Über die von der molekularkinetischen Theorie der Wärme geforderte Bewegung von in ruhenden Flüssigkeiten suspendierten Teilchen," Ann. Phys., vol. 17, no. 8, pp. 549-560, 1905.

[26] R. Ewaschuk and P. D. Turney, "Self-replication and self-assembly for manufacturing," Artif. Life, vol. 12, no. 3, pp. 411-433, 2006

[27] D. J. J. Farnell, T. David, and D. C. Barton, "Numerical model of self-propulsion in a fluid," J. Roy. Soc. Interface, vol. 2, no. 2, pp. 79-88, 2005.

[28] R. A. Freitas, Jr. and R. C. Merkle. (2004). Kinematic Self-Replicating Machines. Landes Bioscience. Georgetown, TX. [Online]. Available: http://www.MolecularAssembler. com/KSRM.htm

[29] T. Fukuda, M. Buss, H. Hosokai, and Y. Kawauchi, "Cell structured robotic system CEBOT: Control, planning and communication methods," Robot. Auton. Syst., vol. 7, no. 2-3, pp. 239-248, 1991.

[30] T. Fukuda and S. Nakagawa, "A dynamically reconfigurable robotic system (concept of a system and optimal configurations), " in Proc. 1987 IEEE Int. Conf. Indust. Electron., Contr. Instrum., Los Alamitos, CA, 1987, pp. 588-595.

[31] T. Fukuda and S. Nakagawa, "Approach to the dynamically reconfigurable robotic system," J. Intell. Robot. Syst., vol. 1, no. 1, pp. 55-72, 1988.

[32] T. Fukuda and S. Nakagawa, "Dynamically reconfigurable robotic system," in Proc. 1988 IEEE Int. Conf. Robot. Autom., Los Alamitos, CA, 1988, vol. 3, pp. 1581-1586.

[33] T. Fukuda and S. Nakagawa, "Method of autonomous approach, docking and detaching between cells for dynamically reconfigurable robotic system CEBOT," JSME Int. J. III-VIB C., vol. 33, no. 2, pp. 263-268, 1990.

[34] T. Fukuda, S. Nakagawa, Y. Kawauchi, and M. Buss, "Self organizing robots based on cell structures-CEBOT," in Proc. 1988 IEEE Int. Workshop Intell. Robots, Los Alamitos, CA, 1988, pp. 145-150.

[35] T. Fukuda, K. Sekiyama, T. Ueyama, and F. Arai, "Efficient communication method in the cellular robotic system," in Proc. 1993 IEEE/RSJ Int. Conf. Intelligent Robots Syst., Los Alamitos, CA, 1993, vol. 2, pp. 1091-1096.

[36] T. Fukuda and T. Ueyama, Cellular Robotics and Micro Robotic Systems. London, U.K.: World Scientific, 1994

[37] T. Fukuda, T. Ueyama, and Y. Kawauchi, "Self-organization in cellular robotic system (CEBOT) for space application with knowledge allocation method," in Proc. 1990 Int. Symp. Artif. Intell. Robot. Autom. Space, Kobe, Japan, 1990, pp. 101-104.
[38] T. Fukuda, T. Ueyama, and K. Sekiyama, "Distributed intelligent systems in cellular robotics," in Artificial Intelligence in Industrial Decision Making, Control and Automation, S. G. Tzafestas and H. B. Verbruggen, Eds. Dordrecht, The Netherlands: Kluwer Academic, 1995, pp. 225-246.

[39] K. Gilpin, K. Kotay, and D. Rus, "Miche: Modular shape formation by self-disassembly," in Proc. 2007 IEEE Int. Conf. Robot. Autom., Los Alamitos, CA, 2007, pp. 2241-2247.

[40] B. Gimi, T. Leong, Z. Gu, M. Yang, D. Artemov, Z. M. Bhujwalla, and D. H. Gracias, "Self-assembled three dimensional radio frequency (RF) shielded containers for cell encapsulation," Biomed. Microdev., vol. 7, no. 4, pp. 341-345, 2005.

[41] S. C. Goldstein, J. D. Campbell, and T. C. Mowry, "Programmable matter," Computer, vol. 38, no. 6, pp. 99-101, 2005.

[42] D. H. Gracias, J. Tien, T. L. Breen, C. Hsu, and G. M. Whitesides, "Forming electrical networks in three dimensions by self-assembly," Science, vol. 289, no. 5482, pp. 1170-1172, 2000.

[43] S. Griffith, D. Goldwater, and J. M. Jacobson, "Self-replication from random parts," Nature, vol. 437, no. 7059, p. 636, 2005

[44] S. T. Griffith, "Growing machines," Ph.D. dissertation, Massachusetts Inst. of Technol., Cambridge, MA, 2004.

[45] R. Groß, M. Bonani, F. Mondada, and M. Dorigo, "Autonomous self-assembly in a swarm-bot," in Proc. 3rd Int. Symp. Auton. Minirobots Res. Edutainment (AMiRE 2005), Berlin, Germany, 2006, pp. 314-322.

[46] R. Groß, M. Bonani, F. Mondada, and M. Dorigo, "Autonomous self-assembly in swarm-bots," IEEE Trans. Robot., vol. 22, no. 6, pp. 1115-1130, 2006

[47] R. Groß and M. Dorigo, "Group transport of an object to a target that only some group members may sense," in Proc. 8th Int. Conf. Parallel Problem Solving From Nature, Berlin, Germany, 2004, vol. 3242, pp. 852-861, ser. Lecture Notes in Computer Science.

[48] R. Groß and M. Dorigo. (2007). Collection of videos of self-assembling systems. [Online]. Available: http://iridia.ulb.ac.be/supp/ IridiaSupp2007-004/

[49] R. Groß and M. Dorigo, "Evolution of solitary and group transport behaviors for autonomous robots capable of self-assembling," Adapt. Behav., to be published.

[50] R. Groß, M. Dorigo, and M. Yamakita, "Self-assembly of mobile robots-From swarm-bot to super-mechano colony," in Proc. 9th Int. Conf. Intell. Auton. Syst., Amsterdam, The Netherlands, 2006, pp. 487-496.

[51] R. Groß, E. Tuci, M. Dorigo, M. Bonani, and F. Mondada, "Object transport by modular robots that self-assemble," in Proc. 2006 IEEE Int. Conf. Robot. Autom., Los Alamitos, CA, 2006, pp. 2558-2564

[52] H. Haken, Synergetics - An Introduction. Berlin, Germany: Springer Verlag, 1978.

[53] A. R. Hemsley, M. E. Collinson, W. L. Kovach, B. Vincent, and T. Williams, "The role of self-assembly in biological systems: Evidence from iridescent colloida sporopollenin in Selaginella megaspore walls," Phil. Trans. Roy. Soc. B, vol. 345 , no. 1312, pp. 163-173, 1994

[54] S. Hirose, "Super mechano-system: New perspective for versatile robotic system," in Proc. 7th Int. Symp. Exper. Robot., Berlin, Germany, 2001, vol. 271, pp. 249-258, ser. Lecture Notes in Control and Information Sciences.

[55] S. Hirose, R. Damoto, and A. Kawakami, "Study of super-mechano-colony (concept and basic experimental setup)," in Proc. 2000 IEEE/RSJ Int. Conf. Intell. Robots Syst., Los Alamitos, CA, 2000, vol. 3 , pp. 1664-1669.

[56] S. Hirose, T. Shirasu, and E. F. Fukushima, "Proposal for cooperative robot 'Gunryu' composed of autonomous segments," Robot. Auton. Syst., vol. 17, no. 1-2, pp. 107-118, 1996.

[57] K. Hosokawa, I. Shimoyama, and H. Miura, "Dynamics of self-assembling systems: Analogy with chemical kinetics," Artif. Life, vol. 1, no. 4, pp. 413-427, 1994.

[58] K. Hosokawa, I. Shimoyama, and H. Miura, "Two-dimensional micro-self-assembly using the surface tension of water," Sensor. Actuat. A - Phys., vol. 57, no. 2, pp. 117-125, 1996.

[59] A. Ishiguro, M. Shimizu, and T. Kawakatsu, "A modular robot that exhibits amoebic locomotion," Robot. Auton. Syst., vol. 54, no. 8, pp. 641-650, 2006.

[60] H. Jacobson, "On models of reproduction," Amer. Sci., vol. 46, pp. 255-284, Sep. 1958.

[61] C. Jones and M. J. Matarić, "From local to global behavior in intelligent self-assembly," in Proc. 2003 IEEE Int. Conf. Robot. Autom., Los Alamitos, CA, 2003, vol. 1, pp. 721-726.

[62] A. Kamimura, H. Kurokawa, E. Yoshida, S. Murata, K. Tomita, and S. Kokaji, "Automatic locomotion design and experiments for a modular robotic system," IEEE/ASME Trans. Mechatron., vol. 10, no. 3, pp. 314-325, 2005.

[63] E. Klavins, "Programmable self-assembly," IEEE Control Syst. Mag., vol. 27, no. 4, pp. 43-56, 2007.

[64] E. Klavins, S. Burden, and N. Napp, "Optimal rules for programmed stochastic self-assembly," in Proc. 2006 Robot. Sci. Syst. Conf., Cambridge, MA, 2007, pp. 9-16, MIT Press.

[65] E. Klavins, R. Ghrist, and D. Lipsky, "A grammatical approach to self-organizing robotic systems," IEEE Trans. Autom. Control, vol. 51, no. 6, pp. 949-962, 2006.

[66] A. N. Knaian, "Design of programmable matter," Master's thesis, Massachusetts Inst. of Technol., Cambridge, MA, 2008.

[67] K. Lee and G. S. Chirikjian, "Robotic self-replication," IEEE Robot. Autom. Mag., vol. 14, no. 4, pp. 34-43, 2007.

[68] A. Lioni and J.-L. Deneubourg, "Collective decision through self-assembling," Naturwissenschaften, vol. 91, no. 5, pp. 237-241, 2004.

[69] A. Lioni, C. Sauwens, G. Theraulaz, and J.-L. Deneubourg, "Chain formation in Ecophylla longinoda," J. Insect Behav., vol. 14, no. 5, pp. 679-696, 2001.

[70] H. Lipson and J. B. Pollack, "Automatic design and manufacture of robotic lifeforms," Nature, vol. 406, no. 6799 , pp. 974-978, 2000.

[71] S. Miyashita, M. Hadorn, and P. E. Hotz, "Water floating self-assembling agents," in Proc. 1st KES Symp. Agent Multi Agent Syst.: Technol. Applicat., Berlin, Germany, 2007, vol. 4496, pp. 665-674, ser. Lecture Notes in Computer Science.

[72] F. Mondada, L. M. Gambardella, D. Floreano, S. Nolfi, J.-L. Deneubourg, and M. Dorigo, "The cooperation of swarm-bots: Physical interactions in collective robotics," 
IEEE Robot. Autom. Mag., vol. 12, no. 2, pp. 21-28, 2005.

[73] F. Mondada, A. Guignard, M. Bonani, D. Bär, M. Lauria, and D. Floreano, "SWARM-BOT: From concept to implementation," in Proc. 2003 IEEE/RSJ Int. Conf. Intell. Robots Syst., Los Alamitos, CA, 2003, vol. 2, pp. 1626-1631.

[74] K. Motomura, A. Kawakami, and S. Hirose, "Development of arm equipped single wheel rover: Effective arm-posture-based steering method," Auton. Robots, vol. 18, no. 2, pp. 215-229, 2005.

[75] S. Murata, K. Kakomura, and H. Kurokawa, "Docking experiments of a modular robot by visual feedback," in Proc. 2006 IEEE/RSJ Int. Conf. Intell. Robots Syst., Los Alamitos, CA, 2006, pp. 625-630.

[76] S. Murata, K. Kakomura, and H. Kurokawa, "Toward a scalable modular robotic system," IEEE Robot. Autom. Mag., vol. 14, no. 4, pp. 56-63, 2007.

[77] S. Murata and H. Kurokawa, "Self-reconfigurable robots," IEEE Robot. Autom. Mag., vol. 14, no. 1, pp. 71-78, 2007.

[78] S. Murata, H. Kurokawa, and S. Kokaji, "Self-assembling machine," in Proc. 1994 IEEE Int. Conf. Robot. Autom., Los Alamitos, CA, 1994, vol. 1, pp. 441-448.

[79] S. Murata, E. Yoshida, A. Kamimura, H. Kurokawa, K. Tomita, and S. Kokaji, "M-TRAN: Self-reconfigurable modular robotic system," IEEE/ASME Trans. Mechatron., vol. 7, no. 4, pp. 431-441, 2002.

[80] S. Murata, E. Yoshida, H. Kurokawa, K. Tomita, and S. Kokaji, "Self-repairing mechanical systems," Auton. Robots, vol. 10, no. 1, pp. 7-21, 2001.

[81] R. Nagpal, "Self-organizing shape and pattern: From cells to robots," IEEE Intell. Syst., vol. 21, no. 2, pp. 50-53, 2006.

[82] J. Nembrini, N. Reeves, E. Poncet, A. Martinoli, and A. Winfield, "Mascarillons: Flying swarm intelligence for architectural research," in Proc. 2005 IEEE Swarm Intell. Symp., Los Alamitos, CA, 2005, pp. 225-232.

[83] M. Nilsson, "Heavy-duty connectors for self-reconfiguring robots," in Proc. 2002 IEEE Int. Conf. Robot. Autom., Los Alamitos, CA, 2002, vol. 4, pp. 4071-4076.

[84] S. Nouyan, R. Groß, M. Bonani, F. Mondada, and M. Dorigo, "Group transport along a robot chain in a self-organised robot colony," in Proc. 9th Int. Conf. Intell. Auton. Syst., Amsterdam, The Netherlands, 2006, pp. 433-442.

[85] R. O'Grady, A. L. Christensen, and M. Dorigo, "Self-assembly and morphology control in a swarm-bot," in Proc. 2007 IEEE/RSJ Int. Conf. Intell. Robots Syst. Los Alamitos, CA, 2007, pp. 2551-2552.

[86] R. O’Grady, R. Groß, A. L. Christensen, F. Mondada, M. Bonani, and M. Dorigo, "Performance benefits of self-assembly in a swarm-bot," in Proc. 2007 IEEE/RSJ Int. Conf. Intell. Robots Syst., Los Alamitos, CA, 2007, pp. 2381-2387.

[87] R. O’Grady, R. Groß, F. Mondada, M. Bonani, and M. Dorigo, "Self-assembly on demand in a group of physical autonomous mobile robots navigating rough terrain," in Proc. 8th Eur. Conf. Artif. Life, Berlin, Germany, 2005, vol. 3630, pp. 272-281, ser. Lecture Notes in Artificial Intelligence.

[88] E. H. Østergaard, K. Kassow, R. Beck, and H. H. Lund, "Design of the ATRON lattice-based self-reconfigurable robot,"
Auton. Robots, vol. 21, no. 2, pp. 165-183, 2006.

[89] K. Payne, B. Salemi, P. Will, and W.-M. Shen, "Sensor-based distributed control for chain-typed self-reconfiguration," in Proc. 2004 IEEE/RSJ Int. Conf. Intell. Robots Syst., Los Alamitos, CA, 2004, vol. 2, pp. 2074-2080.

[90] L. S. Penrose, "Mechanics of self-reproduction," Ann. Human Genet., vol. 23, no. 1, pp. 59-72, 1958.

[91] L. S. Penrose, "Automatic mechanical self-reproduction," New Biol., vol. 28, pp. 92-117, 1959.

[92] L. S. Penrose, "Self-reproducing machines," Sci. Amer., vol. 200, pp. 105-114, Jun. 1959.

[93] L. S. Penrose and R. Penrose, "A self-reproducing analogue," Nature, vol. 179, no. 4571, p. 1183, 1957.

[94] D. Philp and J. F. Stoddart, "Self-assembly in natural and unnatural systems," Angew. Chem. Int. Edit., vol. 35, no. 11 pp. 1154-1196, 1996

[95] A. A. G. Requicha, "Nanorobots, NEMS, and nanoassembly," Proc. IEEE, vol. 91, no. 11, pp. 1922-1933, 2003.

[96] P. W. K. Rothemund, "Using lateral capillary forces to compute by self-assembly," Proc. Nat. Acad. Sci. USA, vol. 97, no. 3, pp. 984-989, 2007.

[97] M. Rubenstein, K. Payne, P. Will, and W.-M. Shen, "Docking among independent and autonomous CONRO self-reconfigurable robots," in Proc. 2004 IEEE Int. Conf. Robot. Autom., Los Alamitos, CA, 2004, vol. 3 , pp. 2877-2882.

[98] D. Rus, Z. Butler, K. Kotay, and M. Vona, "Self-reconfiguring robots," Commun. ACM vol. 45, no. 3, pp. 39-45, 2002.

[99] A. B. Sendova-Franks and N. R. Franks, "Self-assembly, self-organization and division of labour," Phil. Trans. Roy. Soc. B, vol. 354, no. 1388, pp. 1395-1405, 1999.

[100] W.-M. Shen and P. Will, "Docking in self-reconfigurable robots," in Proc. 2001 IEEE/RSJ Int. Conf. Intell. Robots Syst., Los Alamitos, CA, 2001, vol. 2, pp. 1049-1054.

[101] W.-M. Shen, P. Will, and B. Khoshnevis, "Self-assembly in space via self-reconfigurable robots," in Proc. 2003 IEEE Int. Conf. Robot. Autom., Los Alamitos, CA, 2003, vol. 2, pp. 2516-2521.

[102] M. Sitti, "Microscale and nanoscale robotics systems," IEEE Robot. Autom. Mag., vol. 14, no. 1, pp. 53-60, 2007.

[103] K. Støy, "Using cellular automata and gradients to control self-reconfiguration," Robot. Auton. Syst., vol. 54, no. 2, pp. 135-141, 2006.

[104] J. Suthakorn, A. B. Cushing, and G. S. Chirikjian, "An autonomous self-replicating robotic system," in Proc. 2003 IEEE/ASME Int. Conf. Adv. Intell. Mechatron., Los Alamitos, CA, 2003, vol. 1, pp. 137-142.

[105] A. Terfort, N. Bowden, and G. M. Whitesides, "Three-dimensional self-assembly of millimetre-scale components," Nature, vol. 386, no. 6621 pp. 162-164, 1997.

[106] G. Theraulaz, E. Bonabeau, C. Sauwens, J.-L. Deneubourg, A. Lioni, F. Libert, L. Passera, and R. Solé, "Model of droplet dynamics in the Argentine ant Linepithema humile (Mayr)," Bull. Math. Biol., vol. 63, no. 6, pp. 1079-1093, 2001.

[107] J. Tien, T. L. Breen, and G. M. Whitesides, "Crystallization of millimeter-scale objects with use of capillary forces," J. Amer. Chem.
Soc., vol. 120 , no. 48 , pp. 12 670-12 671, 1998.

[108] E. Tuci, R. Groß, V. Trianni, F. Mondada, M. Bonani, and M. Dorigo, "Cooperation through self-assembly in multi-robot systems," ACM Trans. Auton. Adapt. Syst., vol. 1, no. 2, pp. 115-150, 2006.

[109] B. von Haller, A. Ijspeert, and D. Floreano, "Co-evolution of structures and controllers for Neubot underwater modular robots," in Proc. 8th Eur. Conf. Artif. Life, Berlin, Germany, 2005, vol. 3630, pp. 189-199, ser. Lecture Notes in Artificial Intelligence.

[110] P. White, V. Zykov, J. Bongard, and H. Lipson, "Three dimensional stochastic reconfiguration of modular robots," in Proc. 2005 Robot. Sci. Syst. Conf., Cambridge, MA, 2005, pp. 161-168.

[111] P. J. White, K. Kopanski, and H. Lipson, "Stochastic self-reconfigurable cellular robotics," in Proc. 2004 IEEE Int. Conf. Robot. Autom., Los Alamitos, CA, 2004, vol. 3, pp. 2888-2893.

[112] G. M. Whitesides and M. Boncheva, "Beyond molecules: Self-assembly of mesoscopic and macroscopic components," Proc. Nat. Acad. Sci. USA, vol. 99, no. 8, pp. 4769-4774, 2002.

[113] G. M. Whitesides and B. Grzybowski, "Self-assembly at all scales," Science, vol. 295, no. 5564, pp. 2418-2421, 2002.

[114] M. Yamakita. (2004, Oct. 22). Formation control. [Online]. Available: http://www. ac.ctrl.titech.ac.jp/ yamakita/coe/smc.html

[115] M. Yamakita, Y. Taniguchi, and Y. Shukuya, "Analysis of formation control of cooperative transportation of mother ship by SMC," in Proc. 2003 IEEE Int. Conf. Robot. Autom., Los Alamitos, CA, 2003, vol. 1, pp. 951-956.

[116] M. Yim, "Modular self-reconfigurable robotics: What's next?" presented at the U.S.-Korea Conf. Sci. Technol. Entrepren. Durham, NC, 2004. [Online]. Available: http://www.ksea.org

[117] M. Yim, S. Babak, J. Sastra, M. Park, M. Dugan, and C. J. Taylor, "Towards robotic self-reassemby after explosion," in Proc. 2007 IEEE/RSJ Int. Conf. Intell. Robots Syst., Los Alamitos, CA, 2007, pp. 2767-2772.

[118] M. Yim, D. G. Duff, and K. D. Roufas, "PolyBot: A modular reconfigurable robot," in Proc. 2000 IEEE Int. Conf. Robot. Autom., Los Alamitos, CA, 2000, vol. 1, pp. 514-520.

[119] M. Yim, D. G. Duff, and K. D. Roufas, "Walk on the wild side," IEEE Robot. Autom. Mag., vol. 9, no. 4, pp. 49-53, 2002.

[120] M. Yim, K. Roufas, D. Duff, Y. Zhang, C. Eldershaw, and S. B. Homans, "Modular reconfigurable robots in space applications," Auton. Robots, vol. 14, no. 2-3, pp. 225-237, 2003.

[121] M. Yim, W.-M. Shen, B. Salemi, D. Rus, M. Moll, H. Lipson, E. Klavins, and G. S. Chirikjian, "Modular self-reconfigurable robot systems," IEEE Robot. Autom. Mag., vol. 14, no. 1, pp. 43-52, 2007.

[122] M. Yim, Y. Zhang, and D. Duff, "Modular robots," IEEE Spectrum, vol. 39, no. 2, pp. 30-34, 2002.

[123] M. Yim, Y. Zhang, J. Lamping, and E. Mao, "Distributed control for 3D metamorphosis," Auton. Robots, vol. 10, no. 1, pp. 41-56, 2001.

[124] M. Yim, Y. Zhang, K. Roufas, D. Duff, and C. Eldershaw, "Connecting and disconnecting for chain self-reconfiguration with PolyBot," IEEE/ASME Trans. Mechatron., vol. 7, no. 4, pp. 442-451, 2002. 
[125] E. Yoshida, S. Murata, A. Kamimura, K. Tomita, H. Kurokawa, and S. Kokaji, "A self-reconfigurable modular robot: Reconfiguration planning and experiments," Int. J. Robot. Res., vol. 21, no. 10-11, pp. 903-915, 2002

[126] E. Yoshida, S. Murata, S. Kokaji, A. Kamimura, K. Tomita, and H. Kurokawa, "Get back in shape!" IEEE Robot. Autom. Mag., vol. 9, no. 4, pp. 54-60, 2002.

[127] E. Yoshida, S. Murata, K. Tomita H. Kurokawa, and S. Kokaji, "An experimental study on a self-repairing modular machine," Robot. Auton. Syst., vol. 29, no. 1, pp. 79-89, 1999.

[128] Y. Zhang, K. Roufas, C. Eldershaw, M. Yim and D. Duff, "Sensor computations in modular self reconfigurable robots," in Proc. 8th Int. Symp. Exper. Robot., Berlin, Germany, 2003, vol. 5, pp. 276-286 ser. Springer Tracts in Advanced Robotics.

[129] W. Zheng and H. O. Jacobs, "Shape-and-solder-directed self-assembly to package semiconductor device segments,"
Appl. Phys. Lett., vol. 85, no. 16, pp. 3635-3637, 2004.

[130] V. Zykov, E. Mytilinaios, B. Adams, and H. Lipson, "Self-reproducing machines," Nature, vol. 435, no. 7039, pp. 163-164, 2005.

[131] V. Zykov, E. Mytilinaios, M. Desnoyer, and H. Lipson, "Evolved and designed self-reproducing modular robotics," IEEE Trans. Robot., vol. 23, no. 2, pp. 308-319, 2007.

\section{ABOUT THE AUTHORS}

Roderich GroB (Member, IEEE) received the diploma degree (summa cum laude) in computer science from Universität Dortmund, Dortmund, Germany, in 2001 and the doctoral degree in engineering sciences from Université Libre de Bruxelles, Brussels, Belgium, in 2007.

In 2005, he held a short-term JSPS postdoctoral research fellowship at the Department of Control and System Engineering, Tokyo Institute of Technology, Tokyo, Japan. From 2006 to 2007,

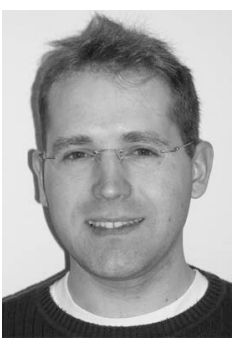
he was a Research Assistant with the School of Biological Sciences, University of Bristol, Bristol, U.K. In 2007, he was a Marie Curie Fellow at Unilever R\&D Port Sunlight, Bebington, U.K. He is currently a Marie Curie Fellow at the Robotic Systems Laboratory, Ecole Polytechnique Fédérale de Lausanne, Switzerland. His research interests include artificial life, computational biology, robotics, and swarm intelligence. He is a member of the Editorial Board of the International Journal of Bio-Inspired Computation and of the Program Committee of numerous international conferences.
Marco Dorigo (Fellow, IEEE) received the laurea (master of technology) degree in industrial technologies engineering and the doctoral degree in information and systems electronic engineering from Politecnico di Milano, Milan, Italy, in 1986 and 1992, respectively, and the degree of Agrégé de l'Enseignement Supérieur from the Université Libre de Bruxelles, Belgium, in 1995.

From 1992 to 1993, he was a Research Fellow with the International Computer Science Institute,

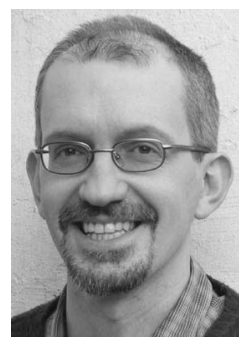
Berkeley, CA. He was a NATO-CNR Fellow in 1993 and a Marie Curie Fellow from 1994 to 1996. Since 1996, he has been a tenured Researcher with FNRS, the Belgian National Fund for Scientific Research, and a Research Director of IRIDIA, the artificial intelligence laboratory of the Université Libre de Bruxelles. He is the inventor of the ant colony optimization metaheuristic. His current research interests include swarm intelligence, swarm robotics, and self-assembling systems.

Dr. Dorigo is the Editor-in-Chief of Swarm Intelligence, and an Associate Editor for IEEE TRANSACTIONS ON EVOLUTIONARY COMPUTATION and ieEe Transactions on Systems, Man, and Cybernetics. He is a member of the Editorial Board of numerous international journals, including $A C M$ Transactions on Autonomous and Adaptive Systems, Adaptive Behavior, Al Communications, Artificial Life, Evolutionary Computation, Journal of Heuristics, Cognitive Systems Research, and Journal of Genetic Programming and Evolvable Machines. In 1996, he received the Italian Prize for Artificial Intelligence, in 2003 the Marie Curie Excellence Award, in 2005 the Dr. A. De Leeuw-Damry-Bourlart award in applied sciences, and, in 2007, the Cajastur International Prize for Soft Computing. 